\title{
Immune cell subset differentiation and tissue inflammation
}

\author{
Pu Fang ${ }^{1}$, Xinyuan Li ${ }^{2}$, Jin Dai ${ }^{1}$, Lauren Cole ${ }^{1}$, Javier Andres Camacho ${ }^{1}$, Yuling Zhang ${ }^{4}$, Yong Ji ${ }^{5}$, Jingfeng Wang ${ }^{4}$, \\ Xiao-Feng Yang ${ }^{1,3}$ and Hong Wang ${ }^{1,3^{*}}$
}

\begin{abstract}
Immune cells were traditionally considered as major pro-inflammatory contributors. Recent advances in molecular immunology prove that immune cell lineages are composed of different subsets capable of a vast array of specialized functions. These immune cell subsets share distinct duties in regulating innate and adaptive immune functions and contribute to both immune activation and immune suppression responses in peripheral tissue. Here, we summarized current understanding of the different subsets of major immune cells, including T cells, B cells, dendritic cells, monocytes, and macrophages. We highlighted molecular characterization, frequency, and tissue distribution of these immune cell subsets in human and mice. In addition, we described specific cytokine production, molecular signaling, biological functions, and tissue population changes of these immune cell subsets in both cardiovascular diseases and cancers. Finally, we presented a working model of the differentiation of inflammatory mononuclear cells, their interaction with endothelial cells, and their contribution to tissue inflammation. In summary, this review offers an updated and comprehensive guideline for immune cell development and subset differentiation, including subset characterization, signaling, modulation, and disease associations. We propose that immune cell subset differentiation and its complex interaction within the internal biological milieu compose a "pathophysiological network," an interactive cross-talking complex, which plays a critical role in the development of inflammatory diseases and cancers.
\end{abstract}

Keywords: Immune cell subset differentiation, T cell, B cell, Dendritic cell, Monocyte, Macrophage, Cardiovascular disease, Cancer

\section{Background}

The innate and adaptive immune system have been traditionally recognized mostly as the cellular response of immune cells, including $\mathrm{T}$ cells (TC), B cells (BC), dendritic cells (DC), monocytes (MC), and macrophages (MØ). During recent decades, molecular immunology research advanced this classical immunology concept with the discovery of subsets of each immune cell lineage. Between 1983 and 1992, the first major immune cell subsets were discovered [1-5]. Following these important breakthroughs, immune subset cell heterogeneity was proposed and its research has been continually flourishing. To date, more than 80 immune cell subsets

\footnotetext{
* Correspondence: hongw@temple.edu

${ }^{1}$ Center for Metabolic Disease Research, Lewis Kats School of Medicine,

Temple University, Medical Education and Research Building, Room 1060,

3500 N. Broad Street, Philadelphia, PA 19140, USA

${ }^{3}$ Department of Pharmacology, Lewis Kats School of Medicine, Temple

University, Philadelphia, PA, USA

Full list of author information is available at the end of the article
}

are recognized [6]. Multiple cytokines and transcription factors have been discovered to control immune cell subset development. Moreover, the concept of immune cell subset plasticity was proposed. For example, pathological conditions could re-shape physiological regulatory $\mathrm{T}$ cells (Treg) into pathological Treg that have weakened immunosuppressive functions [7]. Here, we summarize our current knowledge regarding immune cell heterogeneity with an emphasis on their molecular characteristics and potential contributions to cardiovascular diseases (CVD) and cancers. We hypothesize that different immune cell subsets compose a "pathophysiological network" and an interactive cross-talking complex, which is crucial in the development of human diseases.

(c) The Author(s). 2018 Open Access This article is distributed under the terms of the Creative Commons Attribution 4.0 International License (http://creativecommons.org/licenses/by/4.0/), which permits unrestricted use, distribution, and reproduction in any medium, provided you give appropriate credit to the original author(s) and the source, provide a link to the Creative Commons license, and indicate if changes were made. The Creative Commons Public Domain Dedication waiver (http://creativecommons.org/publicdomain/zero/1.0/) applies to the data made available in this article, unless otherwise stated. 


\section{General processes of hematopoietic stem cell differentiation}

The classical hematopoietic process has been updated in recent years, with the addition of committed common monocyte progenitors (CMoP) and granulocyte-macrophage progenitor (GMP)-independent monocyte-macrophage/ dendritic lineage-restricted progenitor (MDP) arising from common myeloid progenitors (CMP) [8]. Nevertheless, it remains in agreement that the hematopoietic process is conserved among vertebrates [9] and that all hematopoietic lineages are derived from the long-term hematopoietic stem cell (LT-HSC) in bone marrow (BM) (Fig. 1). LT-HSC divisions can result in self-renewal or differentiation into multipotent and lineage-committed hematopoietic progenitor cells, such as common lymphoid progenitors (CLP), CMP, and GMP, all of which lack or have limited self-renewal capacity. CLP differentiate into lymphoid cells ( $T$, B, and natural killer cells), while CMP give rise to megaerythroid cells (platelets and erythrocytes) when GATA-1 is highly expressed. CMP can differentiate into GMP with the expression of "myeloid factor" C/EBP $\alpha$ [10], or differentiate into MDP [8]. GMP could produce "neutrophil-like" inflammatory MC as well as granulocytes. By contrast, MDP could differentiate into common dendritic cell progenitor (CDP) and then DC. MDP also give rise to cMoP, which is

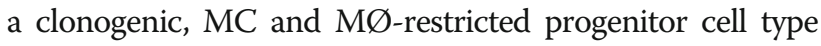
[11]. cMoP further develop into MC, MC-derived MØ, and MC-derived DC. The balance among different immune cell subset differentiation is tightly controlled, the dysregulation of which contributes to both CVDs and cancers. However, significant future studies are still needed to identify more accurate markers for theses immune cell subsets and analyze their differentiation process systemically. Moreover, novel unidentified progenitor subsets still await discovery.

\section{Lymphoid genesis and subset differentiation}

TC development and subset differentiation

CLP migrates from BM to the thymus and differentiate into TC (Fig. 2a). Upon entering the thymus, CLP first become double-negative (DN) thymocytes which do not express the TC co-receptors $\mathrm{CD} 4$ and $\mathrm{CD} 8$, or T cell receptor (TCR). During the DN stage, $\mathrm{CD} 4^{-} \mathrm{CD} 8^{-}$thymocytes gradually lose expression of adhesion molecule CD44 and gain expression of $\alpha$ chain of the IL-2 receptor CD25 on their cell surface, which selects cells that have successfully rearranged their TCR- $\beta$ chain locus. Then, the DN TC starts to express pre-TCR, which is composed of the re-arranged $\beta$ chain and pre- $\alpha$ chain. Pre-TCR expression leads to the double-positive (DP) transition with the expression of both CD4 and CD8 $\left(\mathrm{CD} 4^{+} \mathrm{CD}^{+}\right)$and the subsequent replacement of pre-TCR with TCR (both $\alpha$ chain and $\beta$ chain re-arranged) [12].

The fate of the DP TC depends on signaling that is mediated by interaction of TCR with self-peptide presented by major histocompatibility complex (MHC)

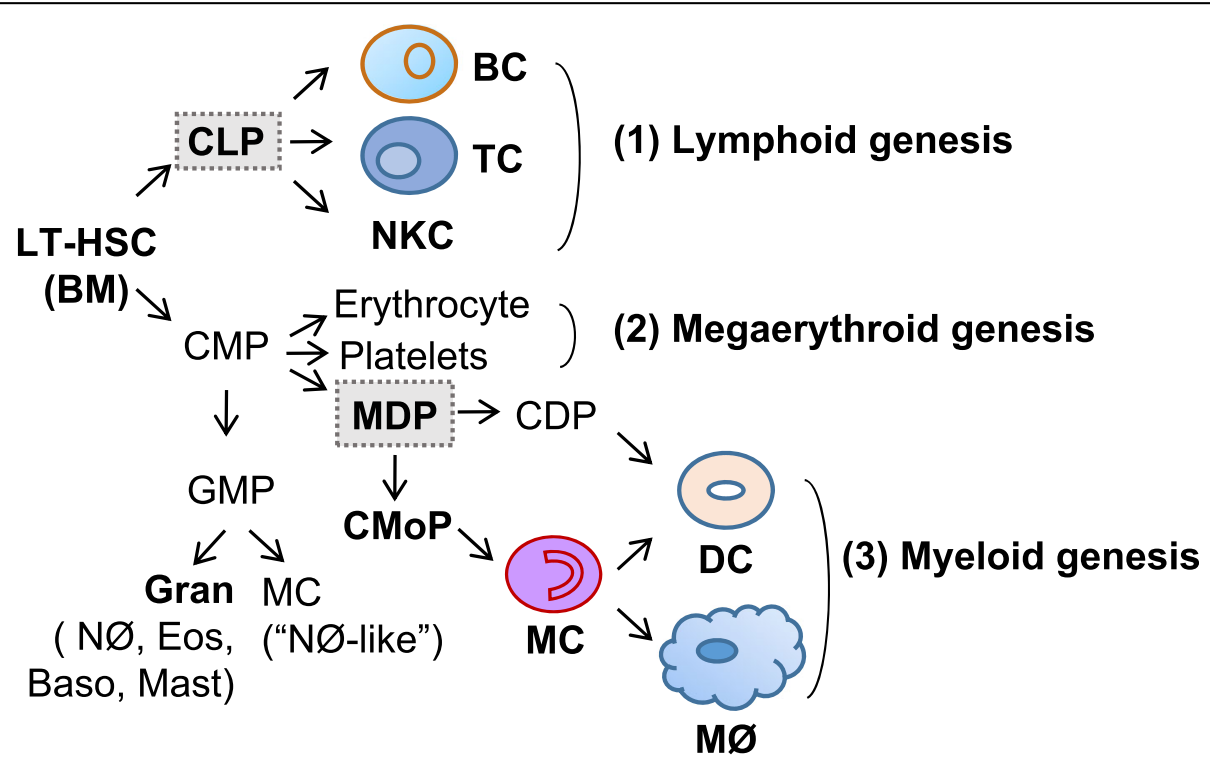

Fig. 1 General processes of hematopoietic stem cell differentiation. Long-term hematopoietic stem cells (LT-HSC) differentiate into common lymphoid progenitors (CLP) and common myeloid progenitors (CMP). CLP are committed to lymphoid genesis and differentiate into B cells (BC), T cells (TC), and natural killer T cells (NKT) (1). CMP are committed to megaerythroid genesis and could differentiate into erythrocytes and platelets (2). CMP could also differentiate into granulocyte-macrophage progenitors (GMP), and then differentiate into granulocytes (neutrophils (NØ), eosinophils, basophils, and mast cells) and "NØ-like" MC. In addition, CMP could differentiate into monocyte-dendritic progenitors (MDP), which are committed to myeloid genesis and differentiate into common dendritic cell progenitor (CDP)-derived plasmocytoid dendritic cells (PDC) and common monocyte precursor (cMoP)derived monocytes $(M C)$, which further differentiate into monocyte-derived $\mathrm{DC}(\mathrm{MDC})$ and macrophages $(\mathrm{M} \varnothing)(3)$ 


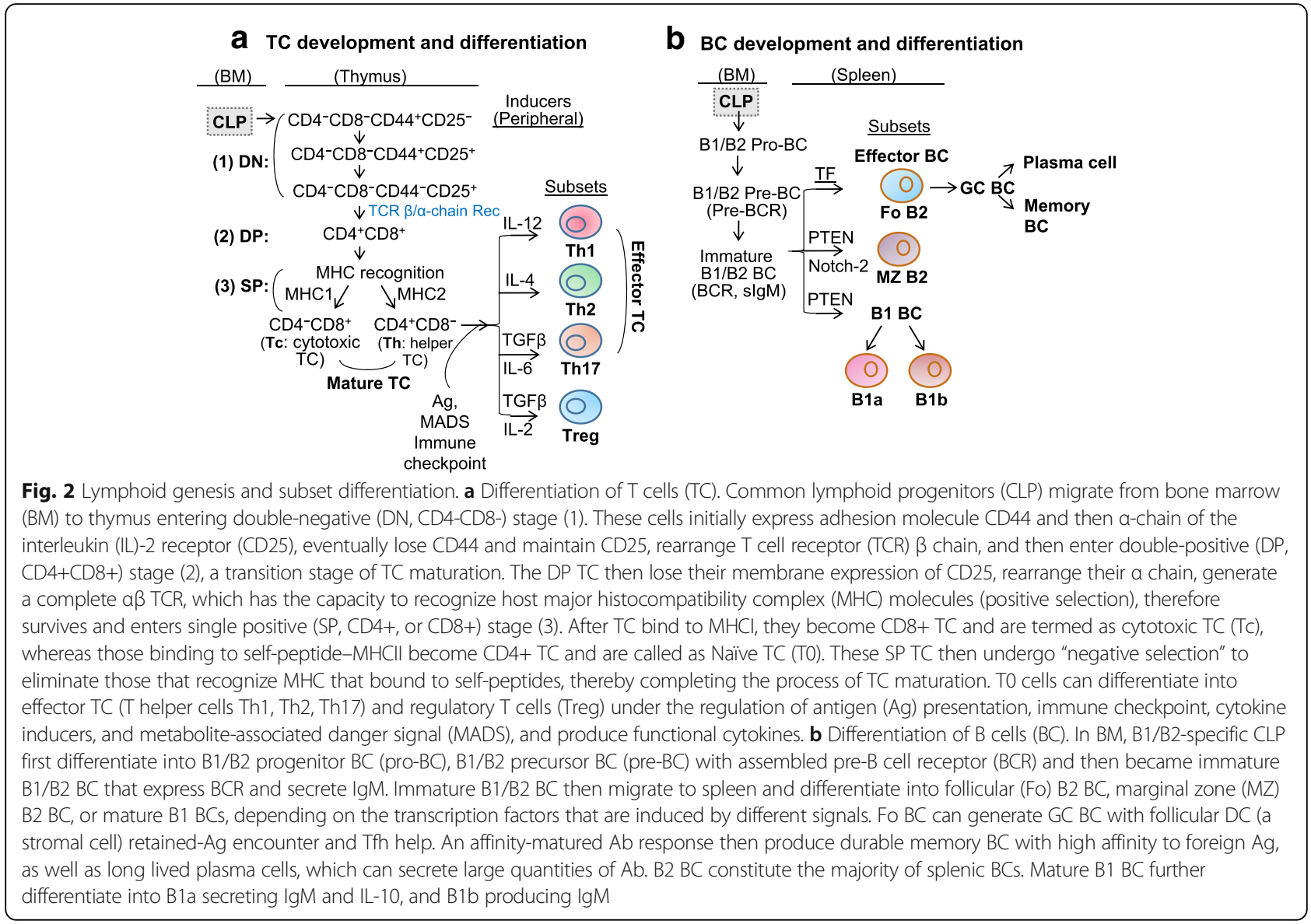

classes. Too little signaling results in delayed apoptosis (death by neglect, positive selection), while too much signaling can promote acute apoptosis (negative selection) $[13,14]$. These DP TC then interact with thymus cortical epithelial cells that express a high density of self-peptide-MHC complexes. DP TC that bind to self-peptide-MHCI complexes become cytotoxic $\mathrm{CD} 8^{+}$ $\mathrm{TC}$, which lose CD4 expression because of signal-interrupted $\mathrm{CD} 8$ downregulation. Whereas those that bind to self-peptide-MHCII ligands become naïve $\mathrm{CD}^{+}{ }^{+} \mathrm{TC}$ which lose CD8 expression because of continued CD8 downregulation. These single-positive (SP) TC are now mature and migrate to peripheral lymphoid sites. Cytotoxic $\mathrm{CD}^{+} \mathrm{TC}$ destroy virus-infected cells and tumor cells, and they are also implicated in transplant rejection. Helper $\mathrm{CD}^{+}{ }^{+} \mathrm{TC}$ assist other leukocytes in immunologic processes, while regulatory $\mathrm{CD} 4^{+} \mathrm{TC}$ maintain immunological tolerance.

The pro-inflammatory Th1 and anti-inflammatory Th2 were discovered in 1989 by Mosmann and Coffman [1]. Then, this Th1/Th2 paradigm was expanded after the discovery of the additional subsets of Th cells, including Treg [15] and IL-17-producing Th17 [16], in the mid-1990s and 2005, respectively.
The subset differentiation of naive $\mathrm{CD} 4^{+} \mathrm{TC}$ is determined by antigen presented by the antigen presenting cell (APC), immune checkpoints co-signaling, cytokines, and metabolism-associated danger signal (MADS) [17]. Different cytokines direct TC to polarize into subtypes. Interleukin (IL)-12 was discovered in the early 1990s to play a major role for the generation of Th1 cells [18]. At the same time, IL-4 was discovered as a critical cytokine for the generation of Th2 cells in vitro [19]. In 2006, $\mathrm{CD}^{+}{ }^{+} \mathrm{TC}$ was found to express IL-17 (designated Th17 cells, a third subset of $\mathrm{T}$ helper cells) in response to the combination of IL-6 and transforming growth factor beta (TGF- $\beta$ ) [20]. Treg are generated when naïve $\mathrm{CD} 4^{+}$ TC are primed with IL- 2 and TGF- $\beta$ [21]. Treg express high levels of forkhead box P3 (FOXP3) and acquire the capacity to suppress TC response. Due to limited information on other $\mathrm{CD}_{4}{ }^{+} \mathrm{TC}$ subsets, including Th9, follicular T (Tfh), and Th22 cells, we only include their characterization information (Table 1).

Interestingly, the differentiation of $\mathrm{CD}^{+} \mathrm{TC}$ into lineages with distinct effector functions is not an irreversible event. Among all these CD4 subsets, Th2, Treg, and Th17 cells are more plastic than Th1 and they may not be stable [7]. For example, Th2 can convert to Th9 in 
Table 1 Characterization of lymphoid cell subsets

\begin{tabular}{|c|c|c|c|c|c|}
\hline Subsets & & Markers & Frequency & Cytokines & Functions \\
\hline \multirow[t]{6}{*}{ TC } & Th1 & 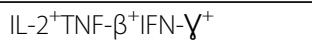 & $20 \%$ in blood CD4+ TC & IL-2, IL-12IFN- $\gamma$, TNF- $a$ & $\uparrow M \varnothing \uparrow C e l l-m e d i a t e d$ immunity \\
\hline & Th2 & $\mathrm{IL}-4^{+} \mathrm{IL}-5^{+} \mathrm{IL}-10^{+} \mid \mathrm{L}-13^{+}$ & $2 \%$ in blood CD4+ TC & IL-4, IL-5, IL-10 IL-25, IL-13 & $\uparrow A b$, Eos $\downarrow M \varnothing$ function \\
\hline & Th17 & IL-17 ${ }^{+}$RORyt ${ }^{+}$ & $0.5 \%$ in blood CD4+ TC & $\begin{array}{l}\text { IL-21, IL-22, IL-24IL-26, IL-17A, } \\
\text { IL-17F }\end{array}$ & Defend host $\uparrow$ Autoimmune disease \\
\hline & Treg & Foxp $3^{+} \mathrm{IL}-10^{+}$ & $5 \%$ in $\mathrm{PBMC}$ & IL-10, TGF- $\beta$ & $\downarrow$ Autoimmune disease \\
\hline & Tfh & $\mathrm{CXCR}^{+}$ & 13.5\% in blood CD4+ TC & $\| \mathrm{L}-21$ & $\begin{array}{l}\uparrow B C \text { activation and functional } \\
\text { differentiation }\end{array}$ \\
\hline & Th22 & $\mathrm{AHR}^{+} \mathrm{CCR} 4^{+} \mathrm{CCR} 6^{+} \mathrm{CCR}_{10} 0^{+}$ & 0.05\%ln blood CD4+ TC & IL-17, IL-22 & $\downarrow$ Immune activation \\
\hline \multirow[t]{2}{*}{ BC } & Fo B2 & $\begin{array}{l}\mathrm{CD} 21 / 35^{\text {int }} \mathrm{CD} 23^{+} \mathrm{CD} 24^{\text {low }} \\
\mathrm{CD} 62 \mathrm{~L}^{+} \mathrm{CD} 93- \\
\text { lgM }\end{array}$ & $4.3 \%$ in blood CD19+ BC & $\lg D, \lg M$ & $\uparrow$ Adaptive response \\
\hline & $\begin{array}{l}\text { MZ B2/B1- } \\
\text { like }\end{array}$ & $\begin{array}{l}\mathrm{CD} 21 / 35^{\text {high }} C D 23- \\
\mathrm{CD} 24^{+} \mathrm{CD}^{-} 3^{-} \lg M^{\text {high }} \lg \mathrm{D}^{\text {low }}\end{array}$ & $17 \%$ in blood $B C$ & $\lg M$ & Respond toblood-borne pathogen \\
\hline
\end{tabular}

CD4+ helper T cells (TC) can be subdivided into seven groups, which include T helper cells Th1, Th2, Th17, regulatory T cells (Treg), Th9, T follicular helper cells (Tfh), and Th22. Th1 drive autoimmune diseases, while Th2 synthesize interleukin (IL)-4, IL-5, IL-6, and IL-1, and facilitate antibody production. Th17 produce IL-17 and play critical roles in autoimmunity and inflammatory diseases. Treg are in charge of suppressing potentially deleterious activities of Th cells. Th9 protect hosts against helminthic infection and also mediate allergic disease. Tfh are known to regulate BC activation and functional differentiation. Th22-secrected IL-22 maintains intestinal epithelial barrier integrity and stimulates the secretion of antimicrobial peptides that limit bacterial dissemination and intestinal inflammation. Bone marrow (BM)-derived B cells (BC) develop into either follicular (Fo) BC or marginal zone (MZ) BC in the spleen. Fo BC participate in TC-dependent immune responses to protein antigens. $M Z B C$ express high levels of $C D 21$ and $C D 1 d$, and respond vigorously to blood borne pathogens. Both $B-1$ a and $B-1 b$ BC seed the peritoneal and pleural cavities. While B-1a BC contribute to innate-like immune responses, B-1b BC contribute to adaptive immunity

response to TGF- $\beta$ stimulation. Treg can switch to Th1 by T-bet, Th2 by interferon regulatory factor 4 (IRF4), Th17 by IL-6+IL21/STAT3, or Tfh by B cell CLL/lymphoma 6 (BCL-6). Similarly, Th17 can convert into interferon gamma (IFN- $\gamma$ )-producing Th1 cells or IL-4-producing Th2 cells when stimulated with IL-12 or IL-4, respectively.

\section{BC development and subset differentiation}

The stages of $\mathrm{BC}$ developmental pathway have been extensively characterized over the past years, revealing important growth factors and regulatory interactions. It was initially described by Lee Herzenberg in 1983 that murine $\mathrm{B} 1$ cells are a unique $\mathrm{CD}^{+} \mathrm{BC}$ subpopulation [2] distinguished from conventional B2 cells by their phenotype, anatomic localization, self-renewing capacity, and production of natural antibodies. As our understanding progresses, interesting differences between B1 and B2 cell subsets have become apparent (Fig. 2b). B1 and B2 development occurs in BM and spleen [22]. In $\mathrm{BM}, \mathrm{CLP}$ develop through $\mathrm{B} 1$ - or $\mathrm{B} 2$-specific pro- $\mathrm{BC}$, pre- $\mathrm{BC}$, and immature $\mathrm{BC}$. During this differentiation process, rearrangements at the immunoglobulin locus result in the generation and surface expression of the pre-B cell receptor (pre-BCR), and finally a mature BCR (comprised of rearranged heavy- and light-chain genes) that is capable of binding antigen. During this stage, $\mathrm{BC}$ undergo a selection process to prevent any self-reactive cells. Cells successfully completing this checkpoint leave bone marrow, eventually maturing into predominant follicular B2 (Fo BC), marginal-zone B2 (MZ BC), B1a, and B1b BC. Fo BC can further develop into germinal center (GC) BC with follicular DC-retained antigen encounter and Tfh help [23]. An affinity-matured antibody response will produce durable memory $\mathrm{BC}$ with high affinity to foreign antigen, as well as long-lived plasma cells, which can secrete large quantities of antibody.

\section{NKC development and subset differentiation}

Both human [24] and mouse [25] studies have shown that NKC can be differentiated from CLP. Three major human NK cell subsets can be distinguished in peripheral blood based on the expression levels of low-affinity Fc-receptor $\gamma$ IIIA (CD16) and neural cell adhesion molecule (NCAM, CD56), namely, CD56 high CD $16^{\text {high/low }}$, $\mathrm{CD} 56^{\text {low }} \mathrm{CD} 16^{\text {low }}$, and $\mathrm{CD} 56^{\text {low }} \mathrm{CD} 16^{\text {high }}$. These subsets are more likely to be NKC at a different stage of maturation. $\mathrm{CD} 56^{\text {high }} \mathrm{CD} 16^{\text {high/low }}$ can be firstly differentiated from BM-derived CLP [26]. These CD56 ${ }^{\text {high }} \mathrm{CD} 16^{\text {high/low }}$ NKC stay within the lymph node and interact with DC or further mature into $\mathrm{CD} 56^{\text {low }} \mathrm{CD} 16^{\text {low }}$, and then became cytotoxic CD56 ${ }^{\text {low }}$ CD16 ${ }^{\text {high }}$ NKC [27].

\section{Myeloid genesis and subset differentiation} DC development and subset differentiation

In 1973, Ralph Steinman and Zanvil Cohn [28, 29] discovered dendritic cells (DC). DC diversity was first acknowledged in 1992 [3]. Murine lymphoid organ DC consist of two subsets, defined by the presence or absence of CD8 expression, each with distinct immune functions [30]. After around another 20 years, CD103 ${ }^{+}$ DC in nonlymphoid tissues was found to be lymphoid $\mathrm{CD}^{+}$DC equivalents, sharing several phenotypic features [31]. More recently, plasmacytoid DC (pDC) were 
uncovered. pDC morphologically resemble plasma cells but, upon exposure to viral stimuli, produce enormous amounts of IFN- $\alpha$ [32]. Importantly, pDC also differentiate upon stimulation into immunogenic DC that can prime TC against viral antigens. To distinguish pDC from the DC that are characterized by Steinman, the latter were renamed classical DC (cDC) and remain so today. Two main subsets of classical $\mathrm{CDC}$ along with $\mathrm{pDC}$ and $\mathrm{MC}$-derived dendritic cell $(\mathrm{mDC})$ all originate from MDP in BM (Fig. 3a). MDP firstly give rise to CDP and $\mathrm{MC}$ in BM. CDP can differentiate into pre-DC, and then become pDC and cDC. Pre-DC migrate from BM, via blood, to lymphoid and nonlymphoid tissues, and constantly replenish $\mathrm{CD}_{103}{ }^{+}$and $\mathrm{CD}_{11 b^{+}} \mathrm{cDC}$ [33]. In $\mathrm{BM}$, pre-DC give rise to immature-pDC, and then pDC [34]. The basic helix-loop-helix (bHLH) transcription factor E2-2 is essential for pDC development in both mice and humans [35]. $\mathrm{mDC}$ can be generated by culturing human or mouse MC with granulocyte-macrophage colony-stimulating factor (GM-CSF) and other cytokines (IL-4, IL-1 $\beta$, IL-6, tumor necrosis factor $\alpha$ [TNF- $\alpha]$, PGE2), which express high levels of CD11c and MHCII, and act as potent antigen-presenting cells [36].

\section{MC/MØ development and subset differentiation}

Human MC are classified by the levels of their surface expression of $\mathrm{CD} 14, \mathrm{CD} 16$, and $\mathrm{CD} 40\left(\mathrm{CD} 14^{++} \mathrm{CD} 16^{-}\right.$, $\left.\mathrm{CD} 14^{++} \mathrm{CD}_{16}{ }^{+}, \mathrm{CD} 14^{+} \mathrm{CD} 16^{++}, \mathrm{CD} 14^{+} \mathrm{CD} 40^{+}\right)$, which differ in their function and phenotype [37]. CD14 $4^{+}$ ${ }^{+} \mathrm{CD} 16^{-} \mathrm{MC}$, also called the classical MC, are the most prevalent MC subset in human blood. The CD14 $4^{+}$ ${ }^{+} \mathrm{CD} 16^{+} \mathrm{MC}$ are intermediate $\mathrm{MC}$ that contribute significantly to atherosclerosis. The $\mathrm{CD} 14^{+} \mathrm{CD} 16^{++} \mathrm{MC}$ are referred to as non-classical $\mathrm{MC}$, which perform a

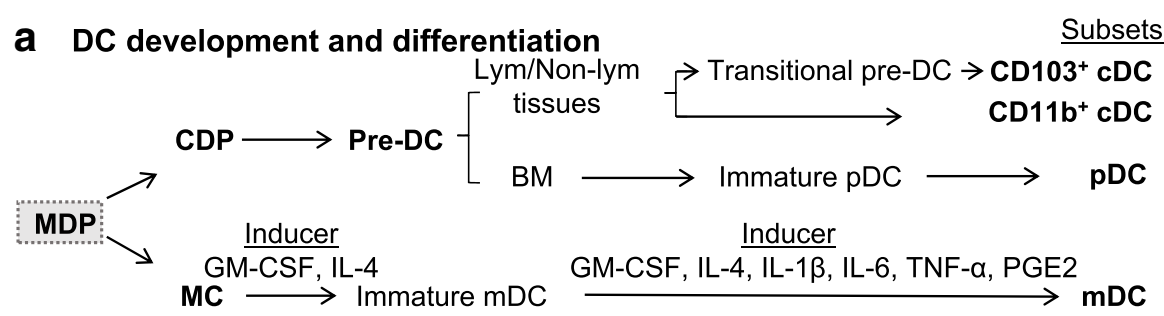

b MC/Mø development and differentiation

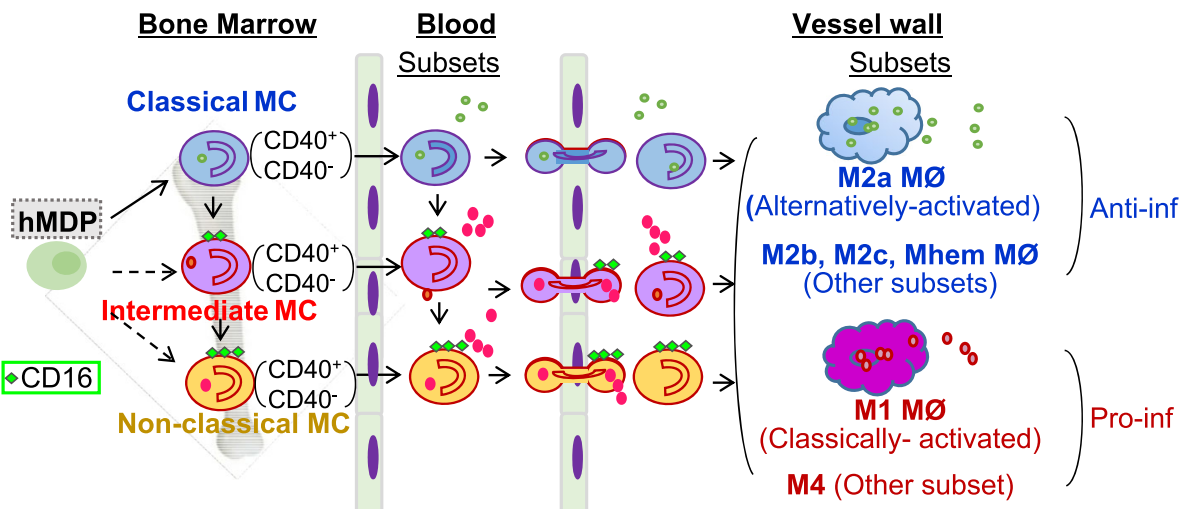

Fig. 3 Myeloid genesis and subset differentiation. a Differentiation of dendritic cells (DC). Monocyte-dendritic progenitors (MDP) are the direct precursors to common dendritic cell progenitors (CDP) and monocytes (MC), which both give rise to DC lineages. In bone marrow (BM), CDP become precursor DC (pre-DC) and differentiate into immature plasmocytoid $\mathrm{DC}(\mathrm{pDC})$ and mature $\mathrm{pDC}$, and then exit the BM traveling through the blood to secondary lymphoid organs and non-hematopoietic tissues. In the lymphoid or non-lymphoid tissues, pre-DC become CD103+ classical/conventional $D C(C D C)$ through transitional pre-cDC stage and CD11 b+ CDC directly. In cultured system, MC differentiate into immature monocyte-derived DC $(\mathrm{mDC})$ in the presence of interleukin (IL)-4 and granulocyte macrophage colony-stimulating factor (GM-CSF). Terminal differentiated mDC are induced upon stimulation with inflammatory cytokines (IL-1, IL-6, and tumor necrosis factor (TNF)) and prostaglandin E2 (PGE2). $\mathbf{b}$ Differentiation of monocytes $(\mathrm{MC})$ /macrophages $(\mathrm{M} \varnothing)$ in human. In the steady state, human classical MC can differentiate into intermediate $\mathrm{MC}$, then patrolling non-classical MC. Classical MC have a high antimicrobial capability due to their potent capacity of phagocytosis. Intermediate MC secrete inflammatory cytokines and have inflammatory properties, whereas non-classical MC mainly patrol along endothelium. During inflammation, all the MC subsets are tethered and penetrate vessel wall and then mature into anti-inflammatory $\mathrm{M} \varnothing(\mathrm{M} 2 \mathrm{a}, \mathrm{M} 2 \mathrm{~b}, \mathrm{M} 2 \mathrm{c}$, and Mhem) and inflammatory M $\mathrm{M}(\mathrm{M} 1$ and $\mathrm{M} 4)$ in tissue. Classical, intermediate and non-classical MC can be further divided into CD40+ and CD40- MC subsets. CD40+ classical/intermediate MC are induced in cardiovascular disease (CVD) and further elevated with the progress of chronic kidney disease (CKD). Dashed arrows indicate potential differentiation pathways, while solid arrows indicate experimentally verified differentiation pathways 
patrolling function. In the steady state, classical $\mathrm{MC}$ can differentiate into intermediate $\mathrm{MC}$, and then further differentiate into patrolling non-classical MC in circulation [38]. During inflammation, all MC subsets invade tissue and then mature to various $\mathrm{M} \varnothing$ subsets according to environmental stimuli. Classical, intermediate, and non-classical $\mathrm{MC}$ can be further divided into $\mathrm{CD} 40^{+}$and $\mathrm{CD} 40^{-} \mathrm{MC}$ subsets. $\mathrm{CD} 40^{+}$classical/intermediate $\mathrm{MC}$ are induced in CVD and further elevated with the progress of chronic kidney disease (CKD) [39] (Fig. 3b).

Although in 1989, it was thought that human peripheral blood MC are a heterogeneous population of leukocytes, distinguishable by the expression of lipopolysaccharide (LPS) receptor CD14 and Fc-receptor $\gamma$ IIIA CD16 [4], it was not confirmed in the murine circulation until 2001 [40]. Mouse MC subsets were originally defined by surface expression of CD11b, lymphocyte antigen 6 complex locus $\mathrm{C} 1$ (Ly6C), and CD62L and lacking CD11c and MHCII [41]. A second MC subset was discovered based on the higher expression of chemokine receptor CX3CR1 in $C x 3 c r 1^{\mathrm{GFP} /+}$ mice [42]. The expression of CX3CR1 was found to be opposite with granulocytic marker Gr1. Later, CX3CR $1^{\text {low }}$ and CX3CR $1^{\text {high }}$ MC (also termed as Gr- $1^{\text {high }}$ and $\mathrm{Gr}-1^{\text {low }} \mathrm{MC}$ ) were defined as Ly6C $\mathrm{C}^{\text {high }}$ and $\mathrm{Ly} 6 \mathrm{C}^{\text {low }}$ $\mathrm{MC}$, respectively. Ly6C is a glycosylphosphatidylinositolanchored glycoprotein associated with homing to lymph nodes function. Gr-1 is composed of Ly6C and Ly6G subunits and its antibody recognize both Ly6C and Ly6G molecules. Ly6C is expressed on both MC and granulocytes, while Ly6G is exclusively expressed on granulocytes. Therefore, a better-justified approach to define mouse MC subsets is to use $\mathrm{Ly}_{6 \mathrm{C}}{ }^{+} \mathrm{Ly} 6 \mathrm{G}^{-}$. This is also the reason that Ly6C, but not Gr-1, is used as mouse MC subset marker [43]. Currently, Ly6 $\mathrm{C}^{\text {high }} \mathrm{MC}$ is determined to be an inflammatory $\mathrm{MC}$ subset, corresponding to human conventional MCs. This subset can also be characterized with a set of surface markers and defined as $\mathrm{CX} 3 \mathrm{CR} 1{ }^{\text {low }} \mathrm{CCR} 2{ }^{+} \mathrm{CD} 62 \mathrm{~L}^{+} \mathrm{CCR} 5{ }^{-}$. In contrast,

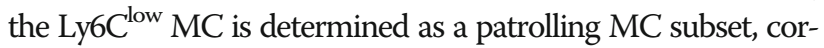
responding to human non-classical $\mathrm{MC}$ and can be characterized as CX3CR1 $1^{\text {high }}, \mathrm{CCR}^{-}, \mathrm{CD}_{2} 2 \mathrm{~L}^{-}$, and $\mathrm{CCR}^{+}$[44]. The Ly6C $C^{\text {high }}$ and Ly6C ${ }^{\text {middle }}$ subsets perform pro-inflammatory functions and are considered the counterpart of human classical MC. The Ly6C $C^{\text {low }}$ subsets patrol along the vascular endothelium. They are involved in tissue repair, which resemble human non-classical MC. In steady state, $\mathrm{Ly} 6 \mathrm{C}^{+} \mathrm{MC}$ differentiate into $\mathrm{Ly}^{-} \mathrm{C}^{-} \mathrm{MC}$ in the circulation. During inflammation, $\mathrm{Ly}_{6} \mathrm{C}^{+} \mathrm{MC}$ are preferentially recruited into inflamed tissue and mature to different $\mathrm{M} \varnothing$ subsets, based on various stimuli.

In 1973, Van Furth reported that pro-inflammatory stimuli elicit MC recruitment and MØ differentiation in tissue [45]. In1992, a new MØ subset, termed "alternative activation" of $M \varnothing$, was identified from IL-4 induced differential gene expression [5]. By contrast, IFN- $\gamma$ and
LPS induced "classical activation" of MØ [46]. As shown in Fig. 3b myeloid precursor MDP give rise to MC within BM. Afterwards, MC exit to the blood, migrate to the tissues under inflammatory conditions, and further differentiate into $\mathrm{M} \varnothing$. Although $\mathrm{BM}$-originated $\mathrm{MC}$ could be the precursors of $M \varnothing$ lineage, tissue $M \varnothing$ could also be derived from embryonic tissue [47], or converted from somatic cells, such as smooth muscle cells [48]. However, different developmental origins of $M \varnothing$ and their functional specificity remain largely unknown.

\section{Granulocyte development and subset differentiation}

Mature granulocytes include neutrophils, eosinophils, basophils, and mast cells, which all develop from GMP. The maturation of neutrophil, eosinophil, and basophil proceeds from GMP to myeloblasts. When primary granules are visible, myeloblasts develop into neutrophil, eosinophil, and basophil myelocytes. When cell division ceases and secondary or specific granules begin to appear, they finally become mature neutrophils, eosinophils, and basophils [49]. Originally described in 1879 by Paul Ehrlich, the origin of mast cell is still a matter of debate [50]. Recently, researchers identified a mast cell progenitor that is derived from BM GMP [51]. The mast cell progenitors transiently circulate in the bloodstream and are capable of migrating to the peripheral tissues, where they mature into connective tissue mast cells or mucosal mast cells, following instructive signals from the tissue environment.

\section{Characterization of immune cell subsets}

Most of the human immune cell subsets have mouse counterparts that share similar functions. We summarized the molecular and functional characterization of currently recognized immune cell subset.

\section{Characterization of lymphoid cell subsets (Table 1) TC subset}

The CD4 ${ }^{+}$TC subsets (Th1, Th2, Th17, Treg, Th9, Th22, and Tfh) differ in their extra-cellular and intracellular markers. Each TC subset releases specific cytokines that can have either pro- or anti-inflammatory functions, and they play either pathogenic or protective functions in human diseases. Th1 produce IFN- $\gamma$ and TNF, and they can activate $M \varnothing$, enhance cell-mediated cytotoxicity, mediate delayed-type hypersensitivity responses, and effectively respond to intracellular pathogens; Th2 release IL-4 (an important survival factor for BC and required for IgG1 and IgE production), IL-5, and IL-13; Th17 produce IL-17 (a strong inducer of autoimmune conditions, such as experimental encephalomyelitis (EAE)); Treg are characterized by the expression of FOXP3 (maintaining expression of FOXP3 transcription factor is needed for the suppressive function of Treg), 
and they secrete immunosuppressive cytokines IL-10 and TGF- $\beta$; Tfh are CD $4^{+} \mathrm{CXCR}^{+}$TC $[52,53]$, and they are known to regulate the activation and differentiation of $\mathrm{BC}$. They preferentially select $\mathrm{BC}$ that present high levels of peptide-MHCII and promote their extensive proliferation or differentiation to antibody-forming cells [54]; Th22 were recently distinguished from Th1 and Th17 by its unique IFN $\gamma$ - and IL-17-independent IL-22 secretion [55]. It is characterized by the expression of CCR4, CCR6, CCR10, and aryl hydrocarbon receptor (AHR). Similar to Th17, Th22 have the capacity to acquire functional features of Th1 [56]. Moreover, within Th22, three more subsets were delineated in human liver, indicating the complexity of the immune cell subset system [57]; Th9 are defined by their production of IL-9 [58], although IL-9 is not unique to Th9. IL-9 is associated with host defense against intestinal nematode infection and the development of allergic responses. They could mediate protection against parasitic infections, while they could also induce allergic inflammation, asthma, and other autoimmune disease.

\section{$B C$ subset}

Fo BC are activated in the spleen follicular niche by TC-dependent antigens of microbial origin. They receive synergistic signals via $\mathrm{BCR}, \mathrm{CD} 40$, and toll-like receptors (TLRs) [59]. Activated Fo BC can further differentiate into GC BC, which express MHC-II and CD27 [60]. GC BC selection can lead to differentiation of antibody secreting plasma cells and memory BC [61]. Marginal zone B2 (MZ $\mathrm{BC})$ are innate-like cells and appear to mediate TC-independent responses to antigens from blood-borne pathogens. MZ $\mathrm{BC}$ can also mediate the transport of antigen from immune complexes into splenic follicles, which is involved in TC-dependent BC responses. Moreover, MZ BC may participate in the immune responses to lipid antigen. Furthermore, they can shuttle between splenic follicle and marginal sinus, and the high level of CD21 expressed on $\mathrm{MZ} \mathrm{BC}$ is presumably evolved to facilitate immune complex capture [59]. B1 BC population has not been clearly defined in humans [62], so our knowledge about the function of B1 BC is based on studies in rodents. B1 BC can contribute to the generation of IgM responses to TC-independent antigens such as phosphorylcholine, an antigen on many pathogenic bacteria [59]. While B-1a BC contribute to innate-like immune responses, B-1b BC contribute to adaptive immunity [63].

\section{Characterization of myeloid cell subsets (Table 2) DC subset}

DC express both MHCI and MHCII molecules [64], and they are unrivaled stimulators of TC. They process protein antigen and initiate antigen-specific cellular immune responses. Recent work has established that tissue DC consist of developmentally and functionally distinct subsets, including $\mathrm{mDC}, \mathrm{pDC}$, and $\mathrm{cDC}$. As genetically distinct DC subsets, they arise from different bone marrow precursors. $\mathrm{mDC}$ are rapidly differentiated from $\mathrm{MC}$ and infiltrate into tissues in response to inflammation. Their role is therefore likely to be more specialized in expediting immune responses [65]. Recently, $\mathrm{mDC}$ are developed as immunotherapy target for treating cancer [66]. pDC accumulate mainly in blood and lymphoid tissues and they enter lymph node through blood circulation. Upon recognition of foreign nucleic acids, they produce massive amounts of type I IFN and acquire the capacity to present foreign antigens [67]. However, chronic inflammatory settings will exhaust pDC through IFN-I and TLR7 [68]. Human and murine $\mathrm{CDC}$ consist of two subsets as defined by the presence or absence of CD103, Xcr1, CD11b, and CD11c expression $\left(\mathrm{CD} 11 \mathrm{c}^{+} \mathrm{Xcr}^{+} \mathrm{CD} 103^{+}\right.$or $\left.\mathrm{CD} 11 \mathrm{c}^{+} \mathrm{CD} 11 \mathrm{~b}^{+}\right)$[30]. CD11c is also expressed on $\mathrm{MC}$ and $\mathrm{M} \varnothing$, which complicates cDC characterization. $\mathrm{CD} 11 \mathrm{c}^{+} \mathrm{Xcr} 1^{+} \mathrm{CD} 103^{+} \mathrm{cDC}$ have superior ability over other $\mathrm{CDC}$ to present microbial antigens [69] and cell-associated antigens $[69,70]$ to $\mathrm{CD}^{+} \mathrm{TC}$.

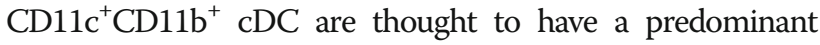
role in $\mathrm{MHCII}$ presentation to $\mathrm{CD}^{+}{ }^{+} \mathrm{TC}$ [71].

\section{MC subset}

Contemporary studies have demonstrated that four subsets of MC reside in the peripheral circulation. These subsets are distinct in their functions and fates [72].

Human MC subpopulations include $\mathrm{CD} 14^{++} \mathrm{CD} 16^{-}$ (classical, which account for $80-90 \%$ of peripheral blood $\mathrm{MC}), \quad \mathrm{CD} 14^{++} \mathrm{CD}_{16}{ }^{+}$(intermediate), $\mathrm{CD} 14^{+} \mathrm{CD} 16^{++}$ (non-classical) subpopulations [73], and $\mathrm{CD} 14^{+} \mathrm{CD} 40^{+}$ (CD40) MC [39]. Classical MC are phagocytic with no inflammatory attributes. The intermediate subtype constitutes a very small percentage in circulation (under physiological conditions); they appear to be transitional $\mathrm{MC}$ that display both phagocytic and inflammatory function. The non-classical subtype displays inflammatory characteristics upon activation and presents antigen [74]. Our lab recently identified $\mathrm{CD} 40^{+} \mathrm{MC}$ as a stronger inflammatory MC subset and a better marker for CKD severity stage compared with intermediate MC subset [39]. We provided evidence suggesting that metabolic risk factors, such as hyperhomocysteinemia (HHcy), induced $\mathrm{CD} 40$ in $\mathrm{MC}$, in a reverse (towards APC) co-stimulation manner [17].

The mouse Ly6C $\mathrm{C}^{\text {middle+high }}$ inflammatory subset corresponds to human $\mathrm{CD} 14^{++} \mathrm{CD} 16^{-}$classical MC, while the mouse Ly $6 \mathrm{C}^{\text {low }}$ patrolling subset corresponds to human $\mathrm{CD}_{14}{ }^{+} \mathrm{CD} 16^{++}$non-classical MC [75]. Microarray-based gene expression profiling has confirmed that differential gene expression profiles observed in mouse monocyte subsets are conserved in human monocyte subpopulations $[73,76]$. Mouse Ly6C $\mathrm{C}^{\text {middle+high }}$ inflammatory MC 
Table 2 Characterization of myeloid cell subsets

\begin{tabular}{|c|c|c|c|c|c|}
\hline Subsets & & Markers & Frequency & Cytokines & Functions \\
\hline \multirow[t]{4}{*}{$\mathrm{DC}$} & $\mathrm{CDC}$ & $\mathrm{CD}_{11 \mathrm{C}^{+} \mathrm{MHCl}}{ }^{+} \mathrm{CD}_{141^{+}}\left(\mathrm{BDCA3}^{+}\right) \mathrm{XCR} 1^{+} \mathrm{CLEC9A}{ }^{+} \mathrm{FLT3}^{+} \mathrm{CD}_{103^{+}}$ & $5 \sim 10 \%$ in blood & $\| \mathrm{IL}-12, \mathrm{IFN}-\mathrm{III}$ & $\uparrow \mid F N-I I C$ Cross-present Ag \\
\hline & & $\mathrm{CD}_{11 \mathrm{c}^{+} \mathrm{MHCl}}{ }^{+}\left(\mathrm{BDCA}^{+}\right) \mathrm{CD} 172 \mathrm{a}^{+} \mathrm{CD} 11 \mathrm{~b}^{+} \mathrm{FLT3}^{+}$ & $45-50 \%$ in blood & IL-23? & Present Ag \\
\hline & $\mathrm{pDC}$ & $\mathrm{BDCA}^{+} \mathrm{LILRA}^{+}{ }^{+} \mathrm{CD} 45 \mathrm{RA}^{+}$ & $45-50 \%$ in blood & IFNa & Sense pathogenActivate IC \\
\hline & $\mathrm{mDC}$ & $\mathrm{MHClI}^{+} \mathrm{CD} 11 \mathrm{c}^{+} \mathrm{CD}_{86}{ }^{+} \mathrm{CD} 40^{+} \mathrm{CD} 80^{+} \mathrm{CD} 83^{+} \mathrm{CCR} 7^{+} \mathrm{CD} 14^{-}$ & $\begin{array}{l}\text { Induced by } \\
\text { inflammation }\end{array}$ & $\begin{array}{l}\text { TNFa, iNOSIL- } \\
12, \text { IL-23 }\end{array}$ & Cross-present Ag \\
\hline \multirow[t]{4}{*}{ MC } & Classical & $\mathrm{CD}_{14}{ }^{+} \mathrm{CD} 16^{-} \mathrm{CXCR}^{+}{ }^{+} \mathrm{CXCR2}{ }^{+} \mathrm{CD} 62 \mathrm{~L}^{+}$ & $80-95 \%$ in MNC & $\begin{array}{l}\text { ROS, NO, } \\
\text { MPOIFN-I, IL-1a, } \\
\text { TNFIL-6, IL-8, } \\
\text { CCL2 }\end{array}$ & Phagocytosis $\uparrow$ Inflammation \\
\hline & Intermediate & $\begin{array}{l}C D 14^{+} C D 16^{+C} D 64^{\text {int }} C C R 1^{\text {int }} C C R 2^{\text {int }} C X 3 C R 1^{\text {int }} C D 11 b^{\text {int }} \\
C D 33^{\text {int }} C D 115^{\text {int }} C D 40^{+} C D 54^{+} H_{L A} \text { AR }\end{array}$ & $2-11 \%$ in MNC & $\begin{array}{l}\text { ROS, NO, } \\
\text { MPOIFN-I, IL-1a, } \\
\text { TNFIL-6, IL-8 } \\
\text { CCL2 }\end{array}$ & 个Inflammation \\
\hline & $\begin{array}{l}\text { Non- } \\
\text { classical }\end{array}$ & $\mathrm{CD} 14^{-} \mathrm{CD} 16^{+}$ & $2-8 \%$ in MNC & $\begin{array}{l}\text { TNF, IL-1ß, } \\
\text { CCL3 }\end{array}$ & Patrol, repair tissue \\
\hline & CD40 & $\mathrm{CD} 14^{+} \mathrm{CD} 40^{+}$ & $64 \%$ in PBMC & TNFa, IL-6 & $\uparrow$ Inflammation \\
\hline \multirow[t]{6}{*}{$M \varnothing$} & M1 & $\mathrm{iNOS}^{+} \mathrm{CXCL} 11^{+} \mid \mathrm{L}-12$ high IL-23 high $\mid \mathrm{L}-10^{\text {low }}$ & $1 \%$ in gastric tissue & $\begin{array}{l}\text { IL-6, TNFaiNOS, } \\
\text { IL-12 }\end{array}$ & Microbicidal $\uparrow$ Inflammation \\
\hline & M2a & $\mathrm{FIZZ1}{ }^{+} \mathrm{Arg} 1^{+}\left|\mathrm{IL}-12^{\text {low }}\right| \mathrm{LL}-23^{\text {low }}$ & $1 \%$ in gastric tissue & $\mathbb{I L}-10$ & $\begin{array}{l}\downarrow \text { InflammationHeal } \\
\text { woundRepair tissue }\end{array}$ \\
\hline & $\mathrm{M} 2 \mathrm{~b}$ & $\mathrm{CD} 80^{\text {high }} \mathrm{CD} 14^{\text {high }}$ HLA-DR $R^{\text {low }}\left|\mathrm{L}-12^{\text {low }}\right| \mathrm{L}-23^{\text {low }}$ & 0 in PBMC & $\mathrm{IL}-10$ & Activate Th2 $\downarrow$ Inflammation \\
\hline & $\mathrm{M} 2 \mathrm{C}$ & CD86 $6^{\text {low }} H L A-D R^{\text {low }} C D 163^{+} T L R 4^{\text {high }} I L-12^{\text {low }} \mid \mathrm{L}-23^{\text {low }}$ & $2.4 \%$ in $\mathrm{CD} 68^{+} \mathrm{M} \varnothing$ & CCL18 & $\begin{array}{l}\downarrow \text { InflammationDeposit } \\
\text { matrixRemodel tissue }\end{array}$ \\
\hline & M4 & $\mathrm{MMP7}^{+} \mathrm{MR}^{+} \mathrm{S} 100 \mathrm{~A}^{+} \mathrm{CD} 8^{+}$ & $\begin{array}{l}31.7 \% \text { in } \mathrm{CD} 68^{+} \mathrm{M} \varnothing \\
\text { from coronary artery }\end{array}$ & $\begin{array}{l}\text { CD86, IL-6, } \\
\text { TNFa }\end{array}$ & $\uparrow$ Inflammation \\
\hline & Mhem & $\mathrm{HOM} \times 1^{+} \mathrm{CD} 163^{+}$ & $\begin{array}{l}25 \% \text { in } \\
\text { thrombosis }\end{array}$ & $\mathrm{IL}-10$ & $\begin{array}{l}\downarrow \text { Lipid accumulationRetain } \\
\text { iron, } \downarrow \text { Inflammation }\end{array}$ \\
\hline
\end{tabular}

Four kinds of dendritic cells (DC) can be defined in human based in part on their functional specialization: monocyte-derived DC (mDC), CD103+ classical/ conventional dendritic cell ( $C D C), C D 11 b+c D C$, and plasmocytoid dendritic cell (pDC). mDC exhibit a strong costimulatory capacity for TC activation. $c D C$ are the most efficient cell type for priming and functional polarization of TC. pDCs can secrete high concentrations of interferon (IFN)-I (mainly IFN-a). In humans, there are three populations of monocytes (MC), as defined by the expression of CD14 and CD16 (CD14++CD16-, CD14+CD16+, and CD14+CD16++). The CD14++CD16$M C$ represent $80 \%$ to $90 \%$ of blood MC, express high levels of the chemokine receptor C-C chemokine receptor type 2 (CCR2) and low levels of CX3C chemokine receptor 1 (CX3CR1), and produce IL-10 rather than TNF and IL-1 in response to lipopolysaccharide (LPS) in vitro. CD14+CD16+ MC express the FC receptors CD64 and CD32, have phagocytic activity, and are entirely responsible for the production of tumor necrosis factor-a (TNF-a) and IL-1 in response to LPS. In contrast, CD14+CD16++ MC lack the expression of other Fc receptors, are poorly phagocytic, and do not produce TNF-a or IL-1 in response to LPS. Our lab recently identified $C D 40+M C$ as a stronger inflammatory subset related to chronic kidney disease (CKD). Macrophages (MØ) also display phenotypic heterogeneity. Depending on the stimuli, MO MØ could polarize towards the pro-inflammatory M1 subset by lipopolysaccharide or IFN- $\gamma$, or towards the alternative M2a type by IL-4. M2b MØs are induced upon combined exposure to immune complexes and Toll-like receptor (TLR) ligands or IL-1 receptor agonists. M2c MØs are induced by IL-10 and glucocorticoids. Atheroprotective Mhem subset could be induced by hemoglobin, and highly express haem oxygenase 1 and CD163. Chemokine (C$\mathrm{X}-\mathrm{C}$ motif) ligand 4 drives differentiation of human specific M4 M $\varnothing$, with unique expression of surface markers such as S100A8, mannose receptor CD206, and matrix metalloproteinase 7

circulate in the blood and egress into tissues following pathological insult, at which point they differentiate into $\mathrm{M} \varnothing$ and DC, producing inflammatory cytokines and reactive oxygen species, stimulating effector TC proliferation, and mediating tissue repair [75]. Ly6 $\mathrm{C}^{\text {low }} \mathrm{MC}$ are characterized by long-range crawling along the luminal surface of small vessels, which allows them to survey for dying and infected cells and mediate their disposal [75]. They also play an important role in mediating live vaccine's protective effects by dictating Tfh differentiation, germinal center formation, and protective antibody production via IL-1 $\beta$ [77]. Furthermore, both $\mathrm{Ly} 6 \mathrm{C}^{+}$and Ly6 $\mathrm{C}^{-} \mathrm{MC}$ can have two sources including GMP and MDP, with distinct gene expression signatures and functions [8].

\section{Mø subset}

MØ are highly heterogeneous cells that can rapidly change their function in response to local microenvironmental signals [78]. Classically activated MØ (M1 MØ) are activated by cytokines such as IFN- $\gamma$ [79]. M1 MØ protect the host from a variety of bacteria, protozoa, and viruses, and they also play critical a role in antitumor immunity [78]. Alternatively activated MØ (M2a MØ) have anti-inflammatory function and regulate wound healing [78]. M2a MØ can secrete large amounts of IL-10 in response to Fc receptor- $\gamma(\mathrm{Fc} \gamma \mathrm{R})$ ligation [80]. Interestingly, $\mathrm{M} 2 \mathrm{a} \mathrm{M} \varnothing$ resembles tumor-associated macrophages (TAM) in cancer, which promote tumor progression by stimulating tumor proliferation, invasion, and metastasis, and inhibiting TC-mediated antitumor 
immune response [81]. The third subset $M 2 b$ are activated when their Fc $\gamma$ Rs bind to LPS $[82,83]$. M2b MØ turn off their production of IL-12 and secrete IL-10. In addition, M2b M $\varnothing$ upregulate antigen presentation and, importantly, promote Th2 responses. The fourth subset $M 2 c$ is induced by IL-10/TGF- $\beta$, which exhibit anti-inflammatory functions in vitro and protect against renal injury in vivo due to their ability to induce Treg [84]. The activation of the fifth subset M4 MØ is M-CSF/CXCL4-dependent [85]. M4 MØ are weakly phagocytic and unable to efficiently phagocytize acetylated LDL (acLDL) or oxidized LDL (oxLDL) [86]. In the context of atherosclerosis, atherosclerotic lesions have been demonstrated to contain M4 MØ, suggesting that M4 MØ may play important roles in the pathology of atherosclerosis [85]. The sixth subset Mox is polarized upon oxidized phospholipid (ox-PL) 1-palmitoyl-2arachidonoyl-sn-glycero-3-phosphorylcholine treatment, which upregulate the expression of oxygenase-1 (HO-1) and thioredoxin reductase 1 (Txnrd1) [87]. This unique Mox $\mathrm{M} \varnothing$ comprised $23 \%$ of the aortic $\mathrm{CD} 11 \mathrm{~b}^{+} \mathrm{F} 4 / 80^{+}$population from 30-week western diet-fed low-density lipoprotein receptor-deficient $\left(\mathrm{Ldlr}^{-1-}\right)$ mice [87]. As Mox MØ express anti-oxidant enzymes HO-1 and Txnrd1, they exert anti-inflammatory actions on vasculature in vivo [85]. This proposed phenotype of Mox MØ closely resembles the phenotypes of the seventh subset Mhem MØ, which generated from hapto-hemoglobin complexes or oxidized red blood cells treatment [88]. CD163 and IL-10 are upregulated in an Nrf2-dependent manner in Mhem $\mathrm{M} \varnothing$ [88]. Mhem MØ promote atherosclerosis development due its angiogenic, vessel permeability causing, and leukocyte attracting properties, through hemoglobin:haptoglobin/CD163/HIF1 $\alpha$-mediated VEGF induction [89].

\section{Representative immune cell subset changes in diseases (Table 3)}

Immune cell subsets play a significant role in the development of various inflammatory diseases and cancers and we have summarized their changes during various disease development (Table 3). Atherosclerosis is a chronic inflammatory pathogenic process of arteries, which leads to cardiovascular diseases (CVDs), including myocardial infarction and stroke [90]. Here, we focused on the discussion of the immune cell changes in atherosclerosis-related diseases. In human studies, the percentage of TC was found to be higher in blood samples from carotid atherosclerotic patients than those from healthy subjects [91, 92]. Similarly, a higher number of subintimal TCs was observed in those patients with carotid atherosclerotic plaque (CAP) [92]. This is also the case in rheumatoid arthritis (RA) [93]. Consistently, the number of natural killer T cell (NKT) was increased in the blood from patients that underwent endarterectomy [91] and those that had colorectal cancer [94]. At the same line, elevated neutrophil count was found to be correlated with increased mortality in patients with acute myocardial infarction (AMI) [95] and stable coronary artery disease (CAD) [96]. In mouse studies, atherosclerotic plaques of $A p o E^{-/-}$mice showed an increase in $\mathrm{CD} 45^{+}$leukocyte content [97]. More specifically, more $\mathrm{TC}$ and less $\mathrm{BC}$ were found in $\mathrm{ApoE}^{-/-}$mice, indicating the functions of these immune cells [98].

\section{TC subsets}

Antigen-specific $\mathrm{CD}^{+}{ }^{+} \mathrm{TC}$ shows impressive anti-tumor effects [99]. Similarly, there is increasing evidence that both $\mathrm{CD}^{+}[93]$ and $\mathrm{CD} 8^{+}[6,93,100] \mathrm{TC}$ are involved in atherosclerosis. More specifically, Th1 and Th17 cell numbers and their related gene expression (T-bet, IFN- $\gamma$, STAT4, ROR $\gamma \mathrm{t}$, STAT3, and IL-17) were significantly increased in acute coronary syndrome (ACS) patients, whereas the Treg cell population, Foxp3 levels, and plasma IL- 10 and TGF- $\beta 1$ were decreased in ACS patients [6]. NKT-like and NKT cells are a small but significant population of $\mathrm{T}$ lymphocytes, and they play an essential role at the very early stages of atherosclerotic plaque development [101]. In atherosclerosis-inducing hyperglycemic diseases (diabetes type 2 or pre-diabetes) [101], endarterectomy at the carotid [91] and colorectal cancer patients [94], the counts of $\mathrm{CD}^{+}$ $56^{+}$NKT-like and NKT cells were significantly higher than those of healthy controls. Moreover, there was an increase of the production of granzyme and perforin in these patients.

In atherosclerotic mice, elevated levels of $\mathrm{CD}^{+} \mathrm{TC}$ were found in lesions $[97,98] . \mathrm{CD}^{+} \mathrm{TC}$ expressing proinflammatory cytokines (IFN- $\gamma$, TNF- $\alpha$, and IL-12) were also found in the atherosclerotic lesions and spleens of high-fat diet-fed $\mathrm{Ldlr}^{-1-}$ [102] or $\mathrm{ApoE}^{-/-}$mice [97]. Importantly, antibody-mediated $\mathrm{CD}^{+}{ }^{+} \mathrm{TC}$ depletion significantly decreased atherosclerotic plaque formation [102]. More specifically, Th1 were significantly increased in $\mathrm{Ldlr}^{-1-}$ mice, correlating with increased lesion formation and smooth muscle cell content [103]. Moreover, the amount of Th2 was reduced in atherosclerotic $\mathrm{Ldlr}^{-/-}$ mice [103]. Furthermore, Th17 quantities were increased in the lesions from $A p o E^{-/-}$mice [104] and in the spleens from obesity mice [105]. In addition, ApoE-/mice exhibit significantly lower numbers of splenic Treg than their wild-type counterparts [106]. Additionally, there was a strong positive correlation between $\mathrm{CD} 4^{+}$ NKT numbers and markers of inflammation in the plaque (including CD3, T-bet, CCR5, and CCR7), indicating that they promote atherogenesis [91]. Finally, effector memory $\mathrm{T}$ cells, including $\mathrm{CD} 4^{+} \mathrm{Th} 1$ and $\mathrm{CD} 8^{+} \mathrm{TC}$, were associated with increased atherosclerosis and CAD [6]. 
Table 3 Representative immune cell subset changes in human diseases

\begin{tabular}{|c|c|c|c|}
\hline Cells & Changes & Tissues & PMID\# \\
\hline \multicolumn{4}{|c|}{ Atherosclerosis (carotid/coronary atherosclerosis, stenosis, cardiovascular death, nonhemorrhagic stroke) } \\
\hline TC & 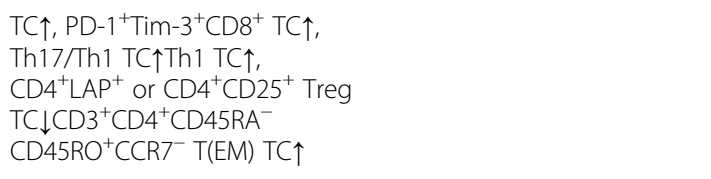 & PBMC & 260352072152475023130116 \\
\hline $\mathrm{BC}$ & $\mathrm{TC} / \mathrm{BC} \uparrow$ & Fibro-fatty (aorta, coronary) & 24122585 \\
\hline & MC & $\begin{array}{l}\mathrm{CD} 14^{++} \mathrm{CD} 16^{+} \mathrm{MC} \uparrow, \mathrm{CD} 14^{++} \mathrm{CD} 16^{-} \mathrm{CCR} 2^{+} \\
\mathrm{MC} \uparrow \mathrm{CD} 14^{+} \mathrm{CD} 16^{++} \mathrm{CCR} 2-\mathrm{MC} \uparrow\end{array}$ & PBMC \\
\hline & 2299972825012963 & MØ & $\mathrm{CD}_{86}{ }^{+} \mathrm{M} 1 \mathrm{M} \varnothing \uparrow, \mathrm{M} 2 \mathrm{M} \varnothing \uparrow$ \\
\hline & PBMC, rupture-prone shoulder regions, Adventitial tissue & 23078881 & \\
\hline \multicolumn{4}{|c|}{ Acute myocardial infarction } \\
\hline TC & $\begin{array}{l}\mathrm{CD}^{+}{ }^{+} \mathrm{CD}^{+} \mathrm{CD} 45 \mathrm{RA}^{-} \mathrm{CD} 45 \mathrm{RO}^{+} \mathrm{CCR} 7^{-} \mathrm{T}(\mathrm{EM}) \mathrm{TC} \uparrow \mathrm{HLA}-\mathrm{DR}^{+} \mathrm{T}(\mathrm{EM}) \\
\mathrm{TC} \uparrow\end{array}$ & PBMC & 23121518 \\
\hline & MC & $\begin{array}{l}\mathrm{CD} 14^{++} \mathrm{CD} 16-\mathrm{CCR} 2^{+} \mathrm{TLR} 4^{+} \\
\mathrm{MC} \uparrow \mathrm{CD} 14^{+} \mathrm{CD} 16^{++} \mathrm{CCR} 2^{+} \mathrm{TLR}^{+} \mathrm{MC} \uparrow\end{array}$ & PBMC \\
\hline & 23121518 & \multicolumn{2}{|c|}{$\begin{array}{l}\text { Hypercholesterolemia (total serum C levels }>200 \mathrm{mg} / \mathrm{dl} \text { or } \\
6.5 \mathrm{mmol} / \mathrm{L}, \mathrm{LDL}-\mathrm{C}>160 \mathrm{mg} / \mathrm{dl} \text {, serum TG } \leq 300 \mathrm{mg} / \mathrm{dl} \text { ) }\end{array}$} \\
\hline TC & $\mathrm{CD}^{+} \mathrm{TC} \uparrow, \mathrm{CD} 4^{+} \mathrm{TC} \uparrow, \mathrm{CD} 8^{+} \mathrm{TC} \uparrow$ & PBMC & 8546748 \\
\hline & $M C$ & $\begin{array}{l}\mathrm{CD} 14^{\text {dim }} \mathrm{CD} 16^{+} \text {non-classical MC } \mathrm{CD} 64^{-} \mathrm{CD} 16^{+} \\
\text {non-classical MC } \uparrow\end{array}$ & PBMC \\
\hline & 103812988977447 & \multicolumn{2}{|c|}{ Infection (HCMV with CAP, HIV on stable ART with CAC) } \\
\hline \multirow[t]{5}{*}{ TC } & 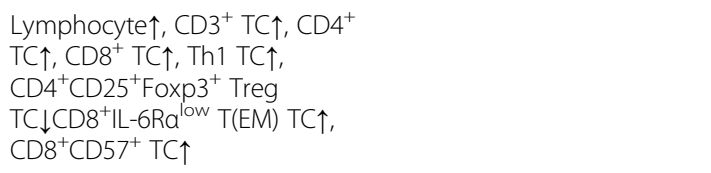 & Subintimal PBMC & 239689792636053027062409 \\
\hline & MC & $\begin{array}{l}\mathrm{CD} 14^{++} \mathrm{CD} 16^{+} \mathrm{MC} \uparrow, \mathrm{CD} 14^{+} \\
{ }^{+} \mathrm{CD} 16-\mathrm{MC} \uparrow \mathrm{CD} 14^{+} \mathrm{CD} 16^{++} \\
\mathrm{MC} \downarrow, \mathrm{CD} 14^{+} \mathrm{CD} 16^{++} \mathrm{MC} \uparrow\end{array}$ & PBMC \\
\hline & 2636053024118494 & Chronic kidney diseases & \\
\hline & MC & $\mathrm{CD} 14^{+} \mathrm{CD} 16^{+}$non-classical MC个 & PBMC \\
\hline & $26,877,933$ & \multicolumn{2}{|c|}{ Early rheumatoid arthritis, systemic lupus erythematosus } \\
\hline TC & $\mathrm{CD}^{+} \mathrm{CD}^{+} 1^{+} \mathrm{CXCR} 4^{+} \mathrm{TC} \uparrow$ & PBMC & 1780453027065298 \\
\hline \multicolumn{4}{|c|}{ Obese, pre-diabetes, diabetes mellitus type 2} \\
\hline TC & $\begin{array}{l}\text { NKT-like } T C \uparrow, \mathrm{CD}^{+}{ }^{+} \mathrm{CD} 56^{+} \mathrm{NKT} \\
\mathrm{TC} \uparrow\end{array}$ & PBMC & 24554505 \\
\hline & MC & $\begin{array}{l}\mathrm{CD} 14^{++} \mathrm{CD} 16^{+} \mathrm{MC} \uparrow \\
\mathrm{CD} 14^{+} \mathrm{CD} 16^{++} \mathrm{MC} \uparrow\end{array}$ & PBMC \\
\hline & 21799175 & \multicolumn{2}{|c|}{ Endarterectomy (CEA and endarterectomy at the femoropopliteal level) } \\
\hline TC & $\mathrm{NKTS \uparrow} \uparrow, \mathrm{TC} \uparrow$ & PBMC, plaques & 27051078 \\
\hline & DC & $\mathrm{CD} 11 \mathrm{~b}^{+} \mathrm{CDC} \uparrow$ & PBMC, plaques \\
\hline & 27051078 & $M \varnothing$ & $\mathrm{MMP}-12^{+} \mathrm{CD} 68^{+} \mathrm{M} \varnothing \uparrow$ \\
\hline & Culprit sections & 23316311 & \\
\hline \multicolumn{4}{|c|}{ Colorectal cancer } \\
\hline TC & NKT cells $\uparrow$ & PBMC & 22220404 \\
\hline
\end{tabular}

\section{BC subsets}

Consistent with TC subset changes, TC/BC ratios were found to be positively correlated with fibro-fatty percentage in the plaque [107]. While B2 BC aggravated atherosclerosis, $\mathrm{B} 1 \mathrm{a}$ and $\mathrm{B} 1 \mathrm{~b} \mathrm{BC}$ were atheroprotective by secreting natural IgM that increased IgM deposits and reduced necrotic cores in atherosclerotic lesions [108]. 
Follicular DC (stromal cells) are an important cell type that help with $\mathrm{BC}$ maturation. They present antigen in activated germinal centers of primary (BM and thymus), secondary (lymph node and spleen), and artery tertiary lymphoid organs, and contribute to innate and adaptive immune responses in atherosclerosis [109].

\section{NKC}

The $\mathrm{CD} 56^{\text {low }} \mathrm{CD} 16^{\text {high }}$ cells comprise the majority of all NKC and are potent mediators of cytotoxicity. By contrast, the $\mathrm{CD} 56^{\text {high }} \mathrm{CD} 16^{\text {high/low }}$ cells have low or no cytotoxicity but produce large amounts of various immunoregulating cytokines. Thus, it is not surprising to observe a significant reduction of $\mathrm{CD} 56^{\text {low }} \mathrm{CD} 16^{\text {high }}$ NKC and a concomitant loss of NKC function in patients with CAD [110].

DC

$\mathrm{CD} 11 \mathrm{~b}^{+} \quad \mathrm{cDC}, \quad \mathrm{CD} 11 \mathrm{c}^{+} \mathrm{MHCII}{ }^{+} \mathrm{CD} 103^{-} \mathrm{CD} 11 \mathrm{~b}^{+} \mathrm{F} 4 / 80^{-}$ $\mathrm{cDC}, \mathrm{CD} 11 \mathrm{c}^{+} \mathrm{MHCII}{ }^{+} \mathrm{CD} 103^{+} \mathrm{CD} 11 \mathrm{~b}^{-} \mathrm{F} 4 / 80^{-} \mathrm{cDC}, \mathrm{CD}$ $11 \mathrm{c}^{+} \mathrm{MHCII}{ }^{+} \mathrm{CD} 103^{-} \mathrm{CD} 11 \mathrm{~b}^{+} \mathrm{F} 4 / 80^{+} \mathrm{mDC}$, and $\mathrm{CD} 11 \mathrm{c}^{+} \mathrm{C}$ $\mathrm{D} 8^{-} \mathrm{CD} 4^{-} \mathrm{cDC}$ were all found to be expanded in atherosclerotic plaque $[91,111]$. In addition, the number of pDC decreased [97].

\section{$\mathrm{MC}$}

$\mathrm{MC}$ are the most abundant immune cell type found in atherosclerotic plaques, indicating that they are crucial promoters of atherogenesis. Classical $\mathrm{CD} 14^{++} \mathrm{CD} 16^{+} \mathrm{MC}$ independently predicted cardiovascular events in coronary atherosclerotic subjects $[100,112,113]$. Based on flow cytometry results, the intermediate monocyte subset $\left(\mathrm{CD} 14^{++} \mathrm{CD} 16^{+}\right)$was increased in atherosclerotic patients when compared with that of healthy subjects [93, 100, $112,114,115]$. Contradictory results were found for non-classical $\mathrm{MC}$ subset $\left(\mathrm{CD} 14^{+} \mathrm{CD} 16^{++}\right)$: it was observed that they were reduced in patients with $\mathrm{CAD}$, compared with those in healthy donor group [113]; however, a majority of studies showed that they were increased in the patients with coronary plaque vulnerability [115], CKD [116], obesity [114], and hypercholesterolemia [117]. Furthermore, $\mathrm{CD} 40^{+} \mathrm{MC}$ number was found to be a useful biomarker for CKD severity [39] and they were induced in metabolic diseases [17].

We and the others have reported that in mice, CD $11 b^{+}{ }^{2} y 6 G^{-}{ }^{-} y 6 C^{\text {middle + high }} \mathrm{MC}$ were consistently and dramatically increased in hypercholesterolemic $\mathrm{ApoE}^{-1-}$ mice that were fed with a high-fat diet [118], in $\mathrm{Ldlr}^{-1-}$ mice [119], in HHcy mice [120], in $m i R 155^{-1-}$ mice [121], and in type 1 diabetes mellitus (T1DM) mice [122]. In addition, resident $C D 11 b^{+} L y 6 G^{-} L^{-} 6 C^{\text {low }} M C$ subset in the circulation was reduced in atherosclerotic mice [121].

\section{Mø}

Specific macrophage subsets have been implicated in atherosclerosis, with M1 MØ dominating the rupture-prone shoulder regions of the plaque and M2 MØ dominating the vascular adventitial tissue [123]. In mouse studies, enhanced M1 MØ polarization was observed in left ventricular remodeling after myocardial infarction (MI) [124] as well as in immune organs from hyperglycemic and HHcy mice [122].

\section{Granulocytes}

Over the past couple of years, studies have provided convincing evidence for the presence of neutrophils in atherosclerotic plaques. It was further revealed that neutrophils aggravate endothelial dysfunction [125], recruit MC [126], activate $M \varnothing$ [127], and destabilize plaque [128], which may be attributed to neutrophil-derived reactive species and proteases. Eosinophils may also have a significant role in coronary atherosclerosis since consistent studies have shown a positive association between eosinophil count and increased risk for future cardiovascular events [129]. Eosinophils may exert their pro-atherosclerotic actions through proteins stored in prominent cytoplasmic granules, which may modulate the acute phase response and innate inflammatory response [130]. Similarly, basophils also promote atherosclerosis via these actions [131]. Mast cells are potent immune cells known for their functions in host defense responses and they drive the development of diseases such as asthma and allergies. Mast cells can exert its effects on atherosclerotic plaque progression and destabilization through their release of mast cell-specific proteases chymase and tryptase, growth factors, histamine, and chemokines [132].

\section{Representative signaling pathways of immune cell subset differentiation \\ TC subset differentiation signaling}

It is now well established that $\mathrm{CD} 4^{+} \mathrm{TC}$ differentiate into four subsets, which are characterized by their distinct cytokine secretion patterns (Fig. 4a). Among the factors controlling such differentiation are the cytokines present in the milieu of the TC during initial priming. In the case of murine Th1 differentiation, APC-derived IL-12 plays a key role in this respect, as shown by the fact that either IL-12 p40 or IL-12R chain knockout mice had highly impaired Th1 responses [133]. In addition, downregulation of the IL-12R $\beta 2$ chain and thus cessation of IL-12 signaling resulted in alternative differentiation into Th2 cells [134]. IL-12/IL-12R activates STAT4, presumably giving rise to IFN- $\gamma$ [135]. IFN- $\gamma$ then activates STAT1/ STAT4 and T-bet, which are essential transcription factors for Th1 cell development [136]. 


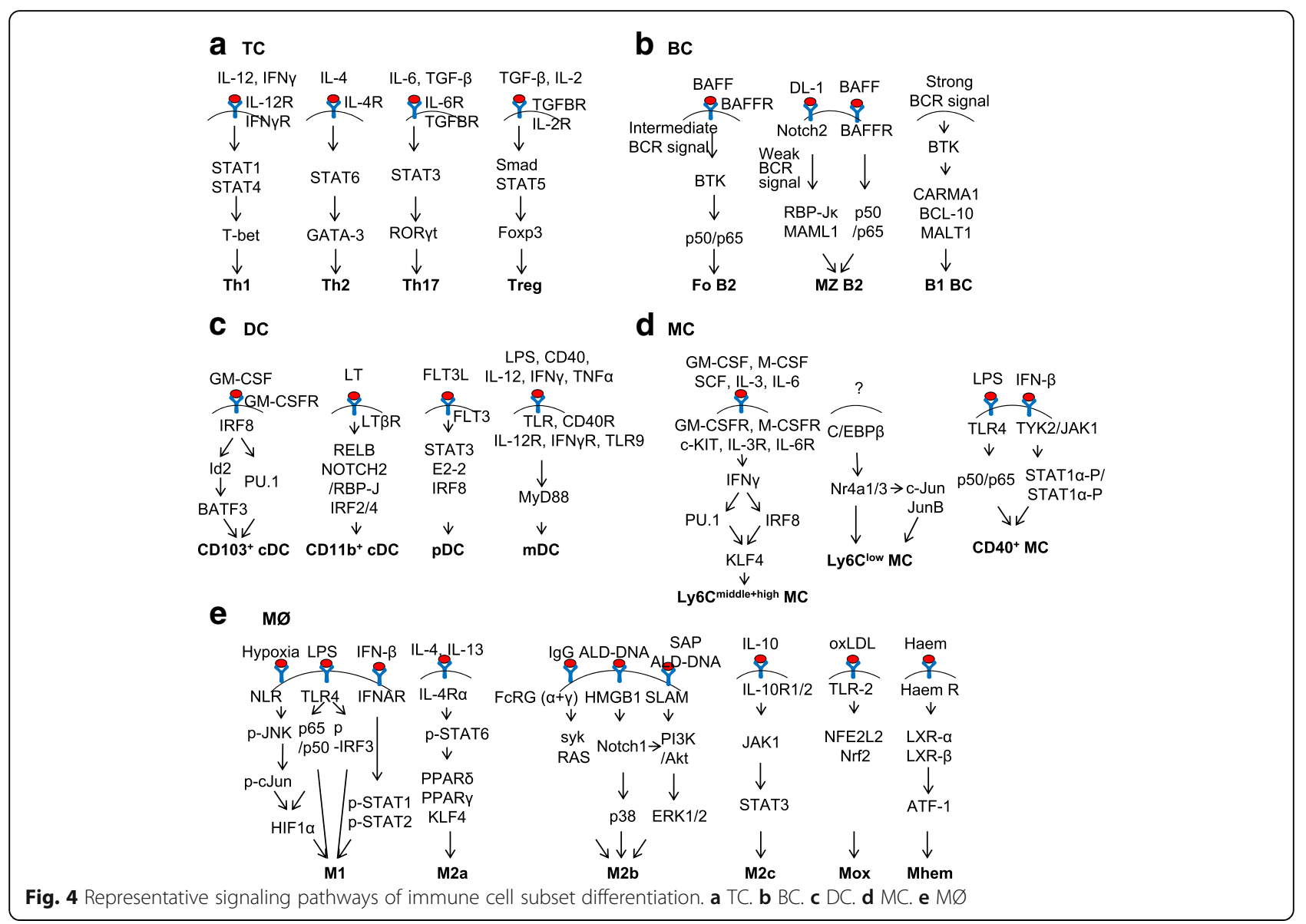

IL-4 is the hallmark cytokine that directs Th2 development, since mice deficient in IL-4 or IL-4R failed to develop a potent population of effector Th2 cells [137]. Ligation of IL-4R by IL-4 results in activation of STAT6, which upregulates expression of the Th2 specific transcription factor GATA-3 [138].

The cytokines that are responsible for the differentiation of naïve mouse TC into Th17 are IL- 6 and TGF- $\beta$ [139]. The combination of IL- 6 and TGF $\beta$ preferentially activates Stat3, which upregulates ROR $\gamma \mathrm{t}$, a critical transcription factor for Th17 cells [140]. Multiple functional ROR $\gamma t$ binding sites are present in the Il17A promoter. Using chromatin immunoprecipitation, RORyt was also found to bind the Il17A gene [141].

TGF $\beta$ plays an important role in Treg differentiation [142]. It induces phosphorylation of Smad3, which stimulates Foxp3 transcription by binding to the transcription control elements of Foxp3 [143]. Treg differentiation is also mediated by IL-2/IL-2R, as IL-2 signaling pathway has been associated with accumulation of Treg in vivo [144]. Upon IL-2/IL-2R activation, phosphorylation of the transcription factor STAT5 appears to play a key role in the generation and expansion of Treg.

\section{$B C$ subset differentiation signaling}

For the transition from immature $\mathrm{BC}$ to $\mathrm{Fo} \mathrm{BC}$, intermediate level of BCR signal is required (Fig. 4b) [145]. After $\mathrm{BCR}$ ligation by antigen, TEC-family protein tyrosine kinase (PTK) BTK5 is recruited and activated [146]. Nuclear factor- $\mathrm{kB}(\mathrm{NF}-\mathrm{kB})$ is an important downstream effector of BCR/BTK5 signaling [145]. The NF- $\mathrm{kB}$ transcription-factor family consists of heterodimers or homodimers of the subunits p50 (NF-kB1), p52 (NF-kB2), c-REL, p65 (RELA), and RELB. The p50/p65 pair determines Fo BC fate. BAFF (B cell-activating factor of the tumor-necrosis-factor family) is also required for Fo BC differentiation. Overexpression of BAFF in transgenic mice induces the production of Fo BC. BAFF engagement activates BTK, which then facilitates BCR-induced activation of the canonical NF- $\kappa B$ pathway.

During MZ BC differentiation, Notch2 interacts with its ligand, Delta-like 1 (DL1), which is specifically expressed by the endothelial cells of red pulp venules in mice [147]. This interaction initiates the cleavage of Notch2, which is not inhibited by weak BCR signaling. The intracellular domain of Notch2 enters the nucleus where it interacts with Mastermind-like 1 (MAML1) and RBP-JK transcription factors. This transcriptional 
complex induces the commitment of $\mathrm{BC}$ towards $\mathrm{MZ}$ $B C$ [147]. BAFF/BAFF-R interaction also delivers survival signals through canonical NF-KB activation in $\mathrm{MZ}$ BCs [148].

A stronger BCR/BTK signal is required for the generation of B1 BC [145], which is supported by the phenotypes of Btk-deficient mice [149]. BTK signals through CARMA1, BCL-10 (B cell lymphoma 10), and MALT1 (mucosa-associated lymphoid tissue lymphoma translocation protein 1), which are critical in the development of B1 cells [150]. Interestingly, B1 cell formation is unaffected by impaired BAFF signaling, raising the possibility that elevated $\mathrm{BCR}$ signaling in these cells or other microenvironmental factors in the pleural cavity where $\mathrm{B} 1 \mathrm{BC}$ reside may be important for BAFF-independent survival [151].

\section{DC subset differentiation signaling}

Development of $\mathrm{CD}_{103}{ }^{+} \mathrm{cDC}$ is orchestrated by the transcription factors including inhibitor of DNA binding 2 (ID2), interferon regulatory factor 8 (IRF8), basic leucine zipper ATF-like 3 transcription factor (BATF3), BCL2, and PU.1 (Fig. 4c) [152, 153]. Deletion of any of these genes leads to a severe developmental defect of $\mathrm{CD}_{103^{+}} \mathrm{DC}[70,154,155]$. The hierarchy and sequential involvement of these specific transcription factors is emerging [153]: IRF8 is required for $\mathrm{CD} 103^{+} \mathrm{cDC}$ differentiation [156]. It was shown that Irf8-deficient DC progenitors had reduced expression of several important transcription factors, including ID2 and BCL2 [157]. Id2 is induced in vitro by granulocyte-macrophage colony-stimulating factor (GM-CSF) and is required in vivo for the development of $\mathrm{CD}_{103^{+}} \mathrm{DC}$ [155]. IRF8 is obligatory for the development of ID2-expressing DC precursors, while BATF3 is induced at later maturation stages of $\mathrm{CD} 103^{+} \mathrm{cDC}$ [70]. It is not clear if all of IRF8's actions in regulating $\mathrm{CD}_{103^{+}} \mathrm{cDC}$ development are mediated by BATF3. More likely, IRF8 acts to control both PU.1-dependent and BATF3-dependent target genes in cDC development [153]. Notably, $\mathrm{CD}_{103}{ }^{+} \mathrm{DC}$ are required for the recruitment of tumor-infiltrating lymphocytes (TILs). It has been shown that melanoma-intrinsic WNT/ $\beta$-catenin signaling pathway was responsible for inhibiting the crosstalk between TILs and $\mathrm{CD}_{103}{ }^{+} \mathrm{DC}$ [158]. It was later found that in a tumor model resembling non-T cell-inflamed human tumors, adoptive transferred $\mathrm{T}$ cells failed to traffic into tumor site due to the absence of $\mathrm{CD}_{103^{+}} \mathrm{DC}$ secreting CXCL9 and CXCL10. As a result, TILs highly expressing CXCR3, which is the receptor for CXCL9 and CXCL10, could not be recruited to the tumor site [159]. Taken together, these results indicated that absence of $\mathrm{CD} 103^{+} \mathrm{DC}$ from the tumor microenvironment may be a dominant mechanism of resistance to cancer immunotherapies.
The transcription factors that control general CD11b ${ }^{+}$ cDC development include RELB [160], NOTCH2 [161], RBP-J [162], IRF2 [163], and IRF4 [164]. Of note, IRF4 also controls functional aspects of CD11b ${ }^{+} \mathrm{DC}$, such as their MHC presentation [165] and migration [166]. Consistent with the notion that $\mathrm{CD}_{11 b^{+}} \mathrm{cDC}$ are heterogeneous, deficiency of IRF4 or NOTCH2 only partially impaired $\mathrm{CD}_{11 \mathrm{~b}^{+}} \mathrm{DC}$ development $[161,166]$. In contrast to $\mathrm{CD} 103^{+} \mathrm{cDC}$, the hierarchy of transcription fac-

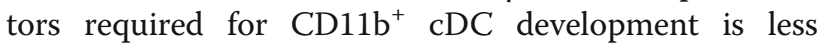
known [152]. Splenic CD11b ${ }^{+}$DC were recognized to comprise two subpopulations that are distinguished by ESAM expression [153]. Only the $\mathrm{ESAM}^{+}$subsets of $\mathrm{CD}_{11} \mathrm{~b}^{+} \mathrm{cDC}$ are dependent on signaling from the lymphotoxin (LT) $\beta$ receptor/Notch2/RBP-J, as deletion of $R b p-J$, using a CD11c-Cre deleter strain in mice led to a $50 \%$ reduction in the $\mathrm{CD}_{11 \mathrm{~b}^{+}}$subset of splenic DC [153].

FLT3L and FLT3 constitute the best-characterized growth factor-receptor axis for pDC [167]. STAT3, a key component of the Flt3 signaling pathway, plays a nonredundant role in pDC development [168]. Mice lacking STAT3 have profound reductions in $\mathrm{pDC}$ that cannot be rescued by Flt3L administration. In addition, transcription factor IRF8 plays a critical role in pDC differentiation since $\operatorname{Irf8}^{-/-}$animals lack pDC [156]. Furthermore, E2-2 directly controls the expression of pDC signature genes, while antagonizing several cDC genes, including Id2 [169].

The cytokines and factors that control the differentiation of MCs into $\mathrm{mDC}$ are less well defined, but key requirements appear to be the recognition of bacterial products through TLR and MyD88 [170] or TC activation signals [171].

\section{MC subset differentiation signaling}

IFN-I signaling in hematopoietic cells is required for the generation of Ly6C ${ }^{+} \mathrm{MC}$ (Fig. 4d) [172]. A critical transcription factor that plays a key role in $\mathrm{Ly} 6 \mathrm{C}^{+} \mathrm{MC}$ differentiation is PU.1. PU.1 is critical for early steps of both myeloid and lymphoid development because PU.1-deficient mice lack MC, granulocytes, and BC [173]. Overexpression of PU.1 leads to activation of IRF8 and Kruppel-like factor 4 (KLF4), which are also key transcription factors involved in $\mathrm{Ly} 6 \mathrm{C}^{+} \mathrm{MC}$ development $[174,175]$. KLF4 is directly regulated by IRF8. Chromatin immunoprecipitation sequencing analysis of the Klf4 gene locus showed multiple IRF8 peaks [176]. Moreover, it was found that $I r f 8^{-1-} \mathrm{MC}$ progenitors did not express Klf4 mRNA, and rescue of Klf4 in Irf $8^{-/-}$mouse myeloid progenitor cells restored $\mathrm{MC}$ differentiation. In addition, KLF4 deficiency abolished CCR2 on Ly6C ${ }^{\text {high }}$ MC that is a homing chemokine receptor associated with $\mathrm{Ly} 6 \mathrm{C}^{\text {high }}$ 
MC migration to tissues upon the sensing of inflammatory stimuli [175].

Transcription factor nuclear receptor subfamily 4, group A, member 1 (NR4A1) is required for $\mathrm{Ly}_{6 \mathrm{C}}^{-} \mathrm{MC}$ development $[177,178]$. NR4A1 was highly expressed in Ly6 $\mathrm{C}^{-} \mathrm{MC}$, and $\mathrm{Ly}^{-} \mathrm{C}^{-}$nonclassical MC were missing in the blood, BM, and other tissues of $\mathrm{Nr}_{\mathrm{Na}} \mathrm{1}^{-1-}$ mice [177, 178]. NR4A1 (also called TR3 or Nur77) is a member of the NR4A family of nuclear receptors, which is considered to function in an anti-inflammatory manner in the vasculature. It was also found that MC from $N r 4 a 1^{-1}$ ${ }^{-} \mathrm{Nr}_{\mathrm{Ha}} \mathrm{3}^{-/-}$mice contained lower levels of $c$-Jun and JunB compared with wild-type mice, indicating that the NR4A family likely regulates expression of $c$-Jun and $J u n B$, which are both proto oncogenes, in $\mathrm{MC}$ development [174]. The few non-inflammatory $\mathrm{Ly}^{-} \mathrm{C}^{-} \mathrm{MC}$ remaining in the $\mathrm{BM}$ of $\mathrm{Nr}_{\mathrm{aal}}{ }^{-1-}$ mice are arrested in $\mathrm{S}$ phase of the cell cycle and undergo apoptosis, implying that NR4A1 functions as a master regulator to control the differentiation and survival of anti-inflammatory $\mathrm{Ly} 6 \mathrm{C}^{-}$ monocytes [178].

LPS is a potent inducer of $\mathrm{CD} 40^{+} \mathrm{MC}$ differentiation. The induction of CD40 expression by LPS occurs at the transcriptional level and involves activation of the transcription factors NF- $\kappa B$ and STAT1 $\alpha$. More specifically, LPS directly activates NF- $\mathrm{kB}$ and induces endogenous production of IFN- $\beta$, which then leads to STAT1 $\alpha$ activation, and ultimately CD40 gene expression [179].

\section{$M \emptyset$ subset differentiation signaling}

In respond to various environmental cues, $M \varnothing$ can acquire distinct functional phenotypes via different phenotypic polarization programs (Fig. 4e). M1 differentiation signaling results in the proteosomal degradation of $\mathrm{I}-\mathrm{kB}$ and the release of NF- $\mathrm{kB}$ p $65 / \mathrm{p} 50$ heterodimer from the NF- $k B / I-\kappa B$ complex [180]. The NF- $k B$ p65/ p50 heterodimer is then translocated to the nucleus and binds to the promoters of inflammatory genes. LPS/ TLR4 also phosphorylates and activates the transcription factor interferon-responsive factor 3 (IRF3), which are involved in M1 polarization and M1-associated gene induction [181]. These M1-associated genes include type I interferon, such as IFN- $\beta$. Secreted type I interferons bind to the type I interferon receptor (IFNAR), which leads to phosphorylation and activation of the transcription factor STAT1 and STAT2. The induced STAT1 and STAT2 then mediate the gene expression of CXCL9 and CXCL10 chemokines [182], which are characteristic of classical M1 MØ activation. In addition to binding to TLRs, some pathogen-associated molecular patterns (PAMPs) and danger-associated molecular patterns (DAMPs), such as hypoxia, are also recognized by a family of cytosolic nucleotide-binding receptors and NOD-like receptors (NLRs) [183]. Upon ligand recognition, NLRs undergo conformational changes and self-oligomerization, which is followed by phosphorylation and activation of JNK and c-Jun MAPKs, both of which are essential for activating hypoxia-inducible factor (HIF) $1 \alpha$ [184]. The crucial role of hypoxia in regulating $\mathrm{M} \varnothing$ inflammatory response has been confirmed in mice with myeloid cell-specific deletion of HIF-1 $\alpha$ [185], in which HIF- $1 \alpha$ was found to be essential in regulating myeloid cell glycolytic capacity, survival and function in the inflammatory microenvironment, which are usually avascular and hypoxic [180]. This is in line with the finding that HIF- $1 \alpha$ was induced by NF-kB p65/p50 [186] and plays an important role in modulating $M \varnothing$ phagocytosis of bacteria under sepsis conditions [187].

M2a MØ can be driven by canonical M2a stimuli, such as IL-4 and IL-13 [188]. IL-4 and IL-13 polarize MØs to M2a phenotype via phosphorylation and activation of STAT6 through the IL-4 receptor alpha (IL-4R $\alpha$ ) [180]. The M2a MØ phenotype is then promoted by several transcription factors, including peroxisome proliferator activated receptor $\gamma$ (PPAR $\gamma)$ [189], PPAR $\delta$, and KLF4 [190]. Myeloid-specific deficiency of either PPAR $\gamma$ or KLF-4 resulted in decreased M2a polarization of MØ, leading to accelerated lesion formation in $\mathrm{ApoE}^{-/-}$[191] or $\mathrm{Ldlr}^{-/-}$mice [192]. Moreover, ligation of PPARY by specific PPAR $\gamma$ ligands preferentially resulted in $\mathrm{M} 2 \mathrm{a}$ polarization in mice and in humans [189]. Furthermore, IL-4 and IL-13 strongly increase the production of several different endogenous PPAR ligands, which include 13-HODE, 15-HETE, 15d-GPalpha, and PPAR coactivators (PGC-1), thereby stimulating the PPAR trans-activating activity. Indeed, many of the hallmark IL-4/ IL-13-inducible M2 marker genes, such as macrophage mannose receptor (MMR), Arginase I, CD36, dectin-1, depend on PPAR expression [193].

Activated lymphocyte-derived (ALD)-DNA confer MØ M2b polarization via Notch-1/p38 signaling activation [194]. Notch-1 signaling also facilitates ALD-DNA-induced M2b differentiation via PI3K and ERK1/2 pathway [195]. In addition, the M2c MØ phenotype arises in the presence of anti-inflammatory cytokine IL-10 [196]. IL-10 binds to the IL-10R, which is composed of two chains: IL-10R1 and IL-10R2 [197]. IL-10 binding to the receptor activates the tyrosine kinase JAK1, which leads to the phosphorylation of transcription factor STAT3. STAT3 then dimerizes, enters the nucleus, and activates the transcription of anti-inflammatory genes [198]. In murine atherosclerotic plaques, Kadl et al. described a phenotypically distinct MØ subset called Mox [87]. This subset is induced by oxidized phospholipids, such as oxLDL, and protects the organisms from oxidative stress through nuclear factor (erythroid-derived 2)-like 2 (NFE2L2)-mediated expression of antioxidant enzymes such as HMOX1, thioredoxin reductase 1 (Txnrd1), and 
sulfiredoxin-1 (Sxrn-1). Finally, in human and mouse, haem induces Mhem MØs, which are characterized by increased production of $\mathrm{LXR} \alpha, \mathrm{LXR} \beta$, haem-induced cyclic AMP-dependent transcription factor 1 (ATF1), HMOX1, and ABCA1 [199].

All the immune cell subsets may interact and communicate with each other. For example, when TGF- $\beta$ signaling is deficient in $\mathrm{CD} 11 \mathrm{c}^{+} \mathrm{mDC}$, there would be increased $\mathrm{CD}^{+}, \mathrm{CD}^{+}$, Th1, and Th17 activation and maturation as a result [97]. $\mathrm{CD} 8^{+} \mathrm{TC}$ could also increase monopoiesis and circulating MC levels [102], while Th1 could reduce E06 antibodies that are produced by B1 BC [103]. Moreover, Th17 differentiation relies on IL-6, which is significantly contributed by MØ [105]. Lastly, DC-mediated TLR4/IL-12/IL-10 signaling could polarize Treg, which control GC Tfh-BC axis [200, 201].

\section{Molecular and cellular modulation of immune cell subsets and its impact on atherosclerosis}

Diverse immune cell subsets in the atherosclerotic plaque strongly contribute to the development of atherosclerotic vascular disease in humans and mice (Fig. 5). During an inflammatory response, increased Th1 TC, Th17 TC, B2 BC, mDC, cDC, $\mathrm{Ly}_{6} \mathrm{C}^{+} \mathrm{MC}$, and M1 MØ drive atherogenesis. On the other side, atherosclerotic disease risk factors also promote the differentiation of Treg TC, Ly6C $C^{-}$MC, M2a/b/c MØ, Mox MØ, and Mhem MØ, Th2 TC, B1 BC, and pDC, which regulate the inflammatory response and play anti-atherogenic roles during resolution phase [178].

There are many factors that could interfere with immune cell subset functions. Many in vivo and in vitro studies have established a clear role for IL-4 in inhibiting Th1 cell development [202], while Th1-derived cytokine
IFN- $\gamma$ inhibits Th2 proliferation by interfering with Th2 costimulator, IL-1 [203]. IL-2 signaling via STAT5 constrains Th17 cell generation [204], while IL-6 inhibits TGF- $\beta$-induced Treg differentiation [205]. Specialized subsets of TC, including follicular Treg and Qa-1-restricted $\mathrm{CD}^{+}$Treg control Fo BC responses [206]. Humanized LL2 (Epratuzumab), an IgG1 monoclonal antibody, delivers antibody-dependent cellular cytotoxicity to MZ B2 when it binds CD22, which is strongly expressed on MZ BC in lymphoid tissues ("Epratuzumab in Non-Hodgkin's Lymphomas", [207]). BC-specific deletion of Shp-1 promotes the development of B1a cells and their expansion in the secondary lymphoid organs [208], indicating that Shp-1 is a key negative regulator of B1a BC activation. Ezh2 was shown to be recruited to the promoters of CCL2 and CCL8 genes in human blood MC, resulting in their gene silencing by $\mathrm{H} 3 \mathrm{~K} 27 \mathrm{me} 3$, thus controlling the number of inflammatory Ly6C $\mathrm{C}^{+} \mathrm{MC}$ [209]. West Nile virus infection accelerated migrating BM Ly6C MC differentiation into DC [210]. p21 reprograms M1 $\mathrm{M} \varnothing$ by shifting activating p65-p50 to inhibitory p50-p50 NF- $\mathrm{B}$ pathways, and an M2-like status [211]. M2a polarization induced by IL- 4 are subject to several negative regulation mechanisms: the $\mathrm{SH} 2$-containing tyrosine phosphatases (PTPs) can modulate IL-4 signaling by dephosphorylating JAKs and STAT6 [212], whereas the suppressor of cytokine signaling (SOCS) family, such as SOCS1 and SOCS3, can inhibit the activity of JAKs by blocking the interaction of the JAK catalytic domain with their STAT protein substrates [213]. Importantly, increased IL-10 secretion, accompanied by anti-inflammatory effect exerted by M2a MØ, was found to predominantly impede macrophage M2b polarization [194]. miR-155 represses C/EBP- $\beta$ /arginase-1 signaling,

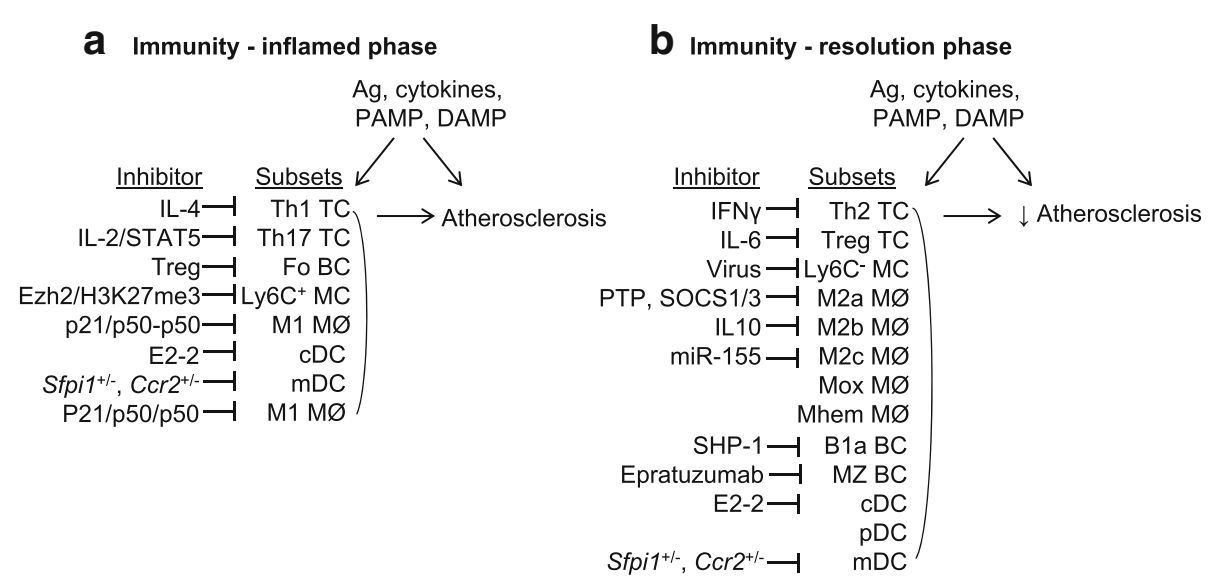

Fig. 5 Molecular and cellular modulation of immune cell subsets and its impact on atherosclerosis. Immune cell subsets play different roles in atherosclerosis and can be suppressed by individual endogenous inhibitors as indicated. a Inflamed phase in immunity. Inflammatory subsets are induced by antigens (Ag), inflammatory cytokines, pathogen-associated molecular patterns (PAMP), danger-associated molecular patterns (DAMP), in inflamed phase of disease and promote atherosclerosis. $\mathbf{b}$ Resolution phase in immunity. Anti-inflammatory subsets are induced in resolution phase of disease and suppress atherosclerosis. There are many inhibitors can could interfere with immune cell subset functions 
which is a hallmark of M2c MØ [214]. Transcription factor E2-2 actively maintains the cell fate of mature pDCs and opposes the "default" cDC fate, in part through direct regulation of lineage-specific gene expression programs [169]. Lastly, Sfpi1 ${ }^{+/-}$or Sfpi1 ${ }^{+-}$mice had reduced differentiation of GM-CSF-dependent mDCs [215].

\section{Molecular and cellular modulation of immune cell subsets and its impact on cancer}

Tumor-entrained neutrophils (TENs) play a crucial pathophysiological role during cancer development. It has been shown that TENs that are distributed in the pre-metastatic niche in the lung tissues could inhibit metastatic tumor seeding in the lung tissues by generating reactive oxygen species [216]. Mechanistically, tumor-secreted CCL2 was shown to be a critical mediator in this process, which is required for optimal anti-metastatic entrainment of G-CSF-stimulated TENs. In addition, TENs are present in the peripheral blood of breast cancer patients prior to surgical resection, but not in healthy individuals. Importantly, the above mechanism is why CD44 variant-positive ROS-resistant cancer stem-like cells tend to be accumulated in the invasive front of the gastric and breast cancer tissues [217].

Immune-checkpoint inhibitors (ICI) have already emerged as successful therapeutic approaches against multiple cancers [218]. Novel strategies which include promoting immunogenic cell death (such as chemotherapy and radiation) and enhancing antigen presentation by stimulating innate immune responses and dendritic cell function (such as IFN-I and TLR ligands) could potentially promote the formation or the presentation of suitable neo-antigens in tumor tissues that have a non-inflamed, immune cell poor tumor microenvironment. In addition, when combined with ICI, blockage of immunosuppressive factors (such as VEGF, IL-10, and TGF- $\beta$ ), which promotes dendritic cell migration, maturation, and function, might lead to better $\mathrm{T}$ cell priming and better immunotherapy against cancers [219].

Myeloid-derived suppressor cells (MDSCs) are a heterogeneous subpopulation of immune cells that are important for inflammatory diseases and cancers [220, 221]. Although MDSCs are present in low quantities in healthy individuals, their numbers are dramatically increased in patients with chronic inflammatory diseases such as cancer, cardiovascular diseases, and autoimmune diseases [220, 222]. MDSCs are generated as a result of sustained and aberrant myeloid cell differentiation. MDSCs are different from terminally differentiated myeloid cells (such as macrophages, dendritic cells, and neutrophils), and they have an activation program that is different from that of mature myeloid cells [223]. MDSCs are characterized by both Gr1 and CD11b

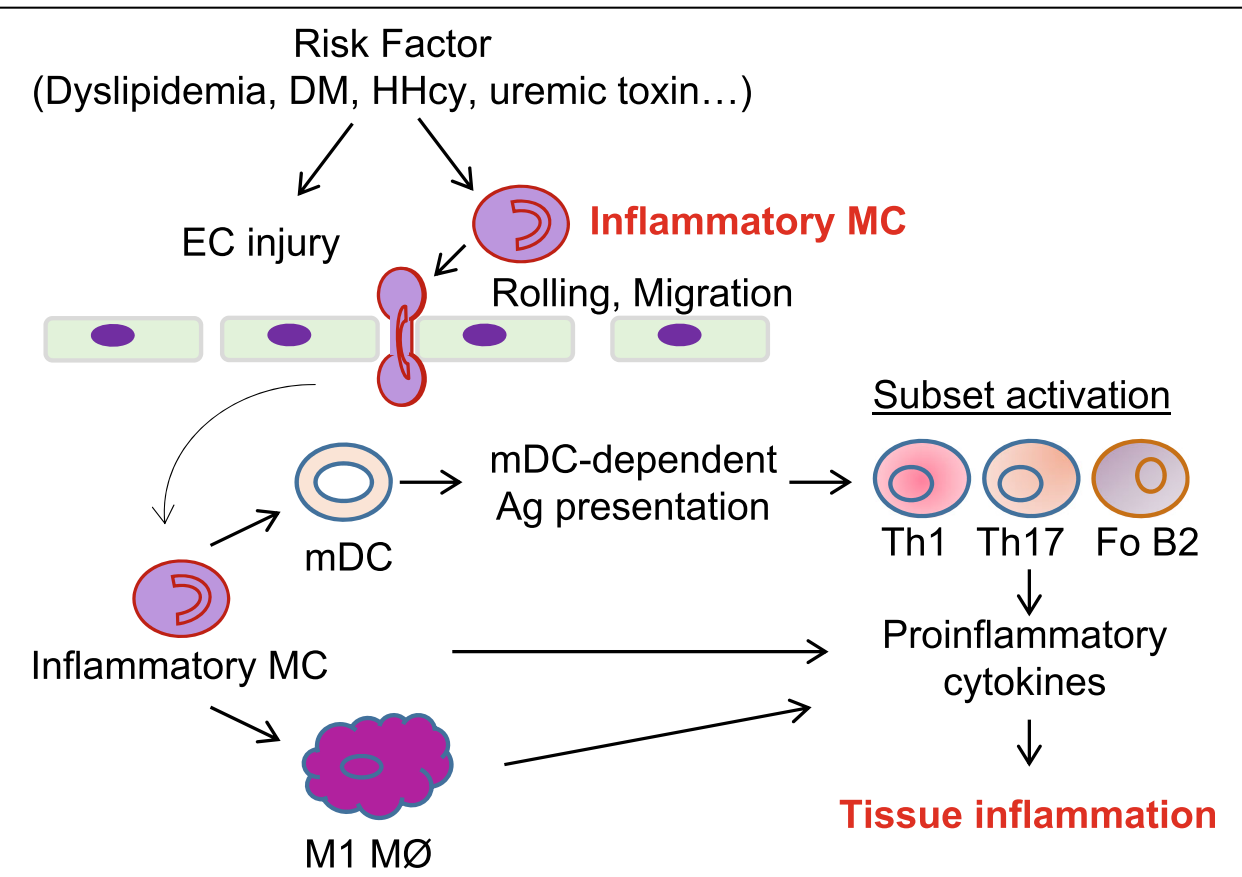

Fig. 6 Model of differentiation of inflammatory mononuclear cell, their interaction with endothelial cells and contribution to lymphocyte subset differentiation and tissue inflammation. In early stage of atherosclerosis, Ly6Cmiddle + high monocytes (MC) transmigrate to sub-endothelial space of vessel and further differentiate to $\mathrm{M} 1$ macrophages $(\mathrm{M} \varnothing)$ and monocyte-derived dendritic cells (mDC). $\mathrm{mDC}$ activate T helper cells Th1, Th17, and B2 cells, resulting in chronic inflammation in atherosclerotic plaque. All of these inflammatory mononuclear cell subsets promote atherosclerosis development partially through production of proinflammatory cytokines 
markers in mice, which can be used to categorize MDSCs into two subpopulations, which include granulocytic (G)-MDSCs (CD11b ${ }^{+}$Ly6G $^{+}$Ly6C $^{\text {low }}$ ) and mono-

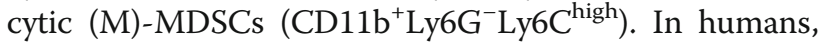
G-MDSCs are characterized by $\mathrm{CD} 11 \mathrm{~b}^{+} \mathrm{CD} 14^{-} \mathrm{CD} 15^{+}$or $\mathrm{CD} 11 \mathrm{~b}^{+} \mathrm{CD} 14^{-} \mathrm{CD}^{-} 6 \mathrm{~b}^{+}$, whereas M-MDSCs are defined as $\mathrm{CD} 11 \mathrm{~b}^{+} \mathrm{CD} 14^{+} \mathrm{HLA}-\mathrm{DR}{ }^{\text {low }} \mathrm{CD} 15^{-}$[223]. MDSCs, rather than $\mathrm{MC}$ or neutrophils, potently suppress immune responses [220]. It has been shown that depletion of MDSCs results in markedly enhanced anti-tumor immune responses [224, 225]. Thus, MDSCs are promising targets of cancer immunotherapy.

IL-6 is a pleiotropic cytokine with varied systemic functions and it plays a critical role in hematopoiesis as a cofactor in stem cell differentiation and amplification [226]. Clinical studies have shown that upregulated serum IL-6 levels in patients were associated with advanced stages of a number of tumors and short survival in patients [227]. Thus, anti-IL-6 antibodies have been used in the treatment of patients with various cancers and inflammatory diseases. Clinically registered IL-6 inhibitors include anti-IL-6 monoclonal antibody (mAb) (siltuximab) and anti-IL6R mAb (tocilizumab). Blocking IL-6 was proven beneficial towards patients with Castleman disease and inflammatory diseases, and it was well tolerated in cancer patients as well. Nevertheless, IL-6 inhibitors showed no efficacy in large randomized trials of various cancers, in particular plasma cell cancers [228]. One possibility of such failure may be related to our incomplete understanding of the role of IL-6 in regulating the differentiation and function of immune cell subtypes. Future studies are warranted to develop better cytokine-based cancer immunotherapy methods.

\section{Summary}

Compelling evidence in human and mouse immune cell heterogeneity research points towards a scenario in which immune cell subsets actively change and modulate the development of CVD and cancers. In this review article, we addressed several issues regarding immune cell subset differentiation, which include general hematopoietic cell differentiation processes, subset development, differentiation process and signaling, characterization, disease relevance, and modulation. We elaborated a working model to elucidate the differentiation of pro-inflammatory mononuclear cells, their interaction with endothelial cells, and their contribution to lymphocyte subset differentiation and tissue inflammation (Fig. 6).

\section{Conclusion}

Immune cells can be sub-divided into various subsets that play specialized roles in innate and adaptive immune responses. Immune cell subset differentiation and its complex interaction within the internal biological milieu compose a "pathophysiological network," an interactive cross-talking complex, which determines and regulates vital conditions of life. Continued research in the understanding of immune cell subsets will provide crucial insights for the etiology, pathobiology, prognosis, and treatment of human CVD and cancers.

\section{Abbreviations}

Ab: Antibody; acLDL: Acetylated low density lipoprotein; ACS: Acute coronary syndrome; Ag: Antigen; AHR: Aryl hydrocarbon receptor; ALD: Activated lymphocyte-derived; Anti-inf: Anti-inflammatory; AP-1: Activator protein 1; APC: Antigen presenting cell; ApoE: Apolipoprotein E; $\mathrm{ApoE}^{-1}$

- CD11CDNR: Functional inactivation of TGF $\beta$ receptor II (TGF $\beta R I I)$ signaling in CD11c + cells; Arg1: Arginase 1; Arg2: Arginase 2; ART: Antiretroviral therapy;

ASK1: Apoptosis signal regulating kinase 1; ATF: Activating transcription factor; BAFF: B cell-activating factor of the tumor-necrosis-factor family; Baso: Basophil; BATF3: Basic leucine zipper ATF-like 3 transcription factor; BC: B cell; BCL: B cell lymphoma; BCR: B cell receptor; BDCA2: Blood DC antigen 2; BHA: Butylated hydroxyanisole; BM: Bone marrow; BST2: Bone marrow stromal antigen 2; BTK: Bruton's tyrosine kinase; C: Cholesterol; C/ EBP: CCAAT-enhancer-binding protein; CAC: Coronary artery calcification; CAD: Coronary artery disease; CAP: Carotid atherosclerotic plaque; CCR2: C-C chemokine receptor type 2; CD11cDNR: Functional inactivation of TGF $\beta$ receptor II signaling in CD11C + cells; CDC: Classical/conventional dendritic cell; Cdkn2a: Cyclin-dependent kinase inhibitor 2A; CDP: Common dendritic cell progenitor; CEA: Carotid endarterectomy; chol: Cholesterol; CKD: Chronic kidney disease; CLP: Common lymphoid progenitor; CMoP: Common monocyte precursor; CMP: Common myeloid progenitor; CRE: Creatinine; CSF-1: Colony stimulating factor 1; CSFR: Colony-stimulating factor receptor; CVD: Cardiovascular disease; CX3CR1: CX3C chemokine receptor 1;

CXCL4: Chemokine (C-X-C motif) ligand 4; DC: Dendritic cell; DC-

SIGN: Dendritic cell-specific intercellular adhesion molecule-3-grabbing nonintegrin; DIO: Diet-induced obesity; DL-1: Delta-like 1; Dnmt1: DNA methyltransferase 1; EAE: Encephalomyelitis; Eos: Eosinophil; FcyR: Fc receptor- $\gamma$ receptor; FIZZ1: Found in inflammatory zone 1; Fli-1: Friend leukemia integration 1; Fo: Follicular; FoxP3: Forkhead box P3; Gata-3: GATA binding protein; GC: Germinal center; GM-CSF: Granulocyte macrophage colony-stimulating factor; GMP: Granulocyte-macrophage progenitor; Gran: Granulocyte; haem: Hemoglobin; HCMV: Human cytomegalovirus; HFD: High-fat diet; HHcy: Hyperhomocysteinemia; HIF1a: Hypoxia-inducible factor 1-a; HLA-DR: Human leukocyte antigen - antigen D related; HIx: H2.0like homeobox protein; hMDP: Human monocyte-dendritic progenitor; HMGB1: High mobility group box 1; HMOX-1: Heme oxygenase 1; HOX1: Homeobox-leucine zipper protein; HSV1: Herpes simplex virus 1; IC: Immunocomplex; ICOSL: Inducible T cell costimulatory ligand; ID2: DNAbinding protein inhibitor 2; ID2: Inhibitor of DNA binding 2; IFN: Interferon; IGF: Insulin-like growth factor; IL: Interleukin; IL-1Ra: Interlukin-1 receptor antagonist; Inf: Inflammatory; iNOS: Inducible nitric oxide synthase; IRF: Interferon regulatory factor; KLF: Kruppel-like factor; LCMV: Lymphocytic choriomeningitis virus; Ldlr: Low density lipoprotein receptor;

LILRA4: Leukocyte immunoglobulin-like receptor, subfamily A, member 4; LPS: Lipopolysaccharide; LT: Lymphotoxin; LT-HSC: Long-term hematopoietic stem cell; Ly6C: Lymphocyte antigen 6 complex locus C1; lym: Lymphoid; MADS: Metabolite-associated danger signal; MALT1: Mucosa-associated lymphoid tissue lymphoma translocation protein 1; MAML: Mastermind like transcriptional coactivator; MAPK: Mitogen-activated protein kinase; MC: Monocyte; MCMV: Murine cytomegalovirus; mDC: Monocyte-derived DC; MDP: Monocyte-dendritic progenitor; MHC: Major histocompatibility complex; MI: Myocardial infarction; miR: MicroRNA; MM: Multiple myeloma; MMP-7: Matrix metalloproteinase-7; MNC: Mononuclear cell;

MØ: Macrophage; MR: Mannose receptor; MZ: Marginal zone; NFAT: Nuclear factor of activated T cells; NFE2L2: Nuclear factor (erythroid-derived 2)-like 2; NF-kB: Nuclear factor kB; NKC: Natural killer cell; NKT: Natural killer T; NØ: Neutrophil; NOI: Nitric oxide intermediates; Nr4a1: Nuclear Receptor Subfamily 4, Group A, Member 1; NSTEACS: Non-ST-elevation acute coronary syndromes; NSTEMI: Non-ST-elevation myocardial infarction; O: Obese; OW: Overweight; oxLDL: Oxidized low density lipoprotein; oxPL: Oxidized phospholipid; PBMC: Peripheral blood mononuclear cell; pDC: Plasmocytoid 
dendritic cell; PGE2: Prostaglandin E2; PMID: PubMed ID; PPAR: Peroxisome proliferator-activated receptor; PTK: Protein tyrosine kinase; PTP: Phosphatase: RA: Rheumatoid arthritis; RBP-J: Recombination signal binding protein for immunoglobulin kappa J region; Rec: Recombination; ROI: Radical oxygen intermediates; RORyt: Retinoic acid receptor-related orphan receptor $\gamma \mathrm{t}$; SA: Stable angina; SAP: Serum amyloid P component; Siglec: Sialic acidbinding immunoglobulin-like lectin; SIRPa: Signal regulatory protein a; SLE: Systemic lupus erythematosus; SOCS: Suppressor of cytokine signaling; STAT: Signal transducer and activator of transcription; STEAMI: ST-elevation acute myocardial infarction; STEMI: ST segment elevation myocardial infarction; T(EM): Effector memory T cell; T1DM: Type 1 diabetes mellitus; T2DM: Type 2 diabetes mellitus; TC: T cell; TCR: T cell receptor; TD: T cell dependent; Tfh: $T$ follicular helper; TG: Triglyceride; TGF $\beta$ : Transforming growth factor $\beta$; Th: T helper cell; THO: Naïve T cell; THBS1: Thrombospondin 1: Throm: Thrombosed; Tl: T cell independent; TLR: Toll-like receptor; TNFa: Tumor necrosis factor-a; Treg: Regulatory T cell; Txnrd1: Thioredoxin reductase 1; UA: Unstable angina; UAP: Unstable angina pectoris; VEGF: Vascular endothelial growth factor; VSV: Vesicular stomatitis virus; a: Anti

\section{Funding}

This work was supported in part by the NIH grants HL117654, HL-110764, HL130233, HL131460, DK104116, and DK113775 to Hong Wang, HL132399, HL138749 to Xiaofeng Yang, T32 Hematopoiesis Training Grant 5T32DK007780 to Xinyuan Li, and AHA SDG 17 SDG33671051 to Pu Fang.

\section{Authors' contributions}

PF and HW drafted the manuscript. XL and XFY participated in the discussion. LC provided the immune cell subset in disease table and language editing. JAC contributed to MC subset differentiation pathways. Other authors revised the manuscript. All authors read and approved the final manuscript.

\section{Ethics approval and consent to participate} Not applicable.

\section{Consent for publication}

Not applicable.

\section{Competing interests}

The authors declare that they have no competing interests.

\section{Publisher's Note}

Springer Nature remains neutral with regard to jurisdictional claims in published maps and institutional affiliations.

\section{Author details}

${ }^{1}$ Center for Metabolic Disease Research, Lewis Kats School of Medicine, Temple University, Medical Education and Research Building, Room 1060, 3500 N. Broad Street, Philadelphia, PA 19140, USA. ${ }^{2}$ Department of Pathology and Laboratory Medicine, University of Pennsylvania, Philadelphia, PA, USA. ${ }^{3}$ Department of Pharmacology, Lewis Kats School of Medicine, Temple University, Philadelphia, PA, USA. ${ }^{4}$ Cardiovascular Medicine Department, Sun Yat-Sen Memorial Hospital, Sun Yat-Sen University, Guangzhou 510120, China. ${ }^{5}$ Key Laboratory of Cardiovascular Disease and Molecular Intervention, Nanjing Medical University, Nanjing, China.

\section{Received: 7 May 2018 Accepted: 2 July 2018}

\section{Published online: 31 July 2018}

\section{References}

1. Mosmann TR, Coffman RL. TH1 and TH2 cells: different patterns of lymphokine secretion lead to different functional properties. Annu Rev Immunol. 1989;7:145-73.

2. Hayakawa K, et al. The "Ly-1 B" cell subpopulation in normal immunodefective, and autoimmune mice. J Exp Med. 1983;157(1):202-18.

3. Vremec $D$, et al. The surface phenotype of dendritic cells purified from mouse thymus and spleen: investigation of the CD8 expression by a subpopulation of dendritic cells. J Exp Med. 1992;176(1):47-58.

4. Passlick B, Flieger D, Ziegler-Heitbrock HW. Identification and characterization of a novel monocyte subpopulation in human peripheral blood. Blood. 1989;74(7):2527-34.
5. Stein $\mathbf{M}$, et al. Interleukin 4 potently enhances murine macrophage mannose receptor activity: a marker of alternative immunologic macrophage activation. J Exp Med. 1992;176(1):287-92.

6. Ammirati $\mathrm{E}$, et al. Effector memory $T$ cells are associated with atherosclerosis in humans and animal models. J Am Heart Assoc. 2012;1 (1):27-41.

7. Yang WY, et al. Pathological conditions re-shape physiological Tregs into pathological Tregs. Burns Trauma. 2015;3(1)

8. Yanez, A., et al., Granulocyte-monocyte progenitors and monocyte-dendritic cell progenitors independently produce functionally distinct monocytes. Immunity, 2017. 47(5): p. 890-902 e4.

9. Jagannathan-Bogdan M, Zon LI. Hematopoiesis. Development. 2013;140(12): 2463-7.

10. Orkin SH, Zon LI. Hematopoiesis: an evolving paradigm for stem cell biology. Cell. 2008;132(4):631-44.

11. Hettinger $\mathrm{J}$, et al. Origin of monocytes and macrophages in a committed progenitor. Nat Immunol. 2013;14(8):821-30.

12. Germain RN. T-cell development and the CD4-CD8 lineage decision. Nat Rev Immunol. 2002;2(5):309-22.

13. Hogquist KA, Baldwin TA, Jameson SC. Central tolerance: learning selfcontrol in the thymus. Nat Rev Immunol. 2005;5(10):772-82.

14. Cho JH, Sprent J. TCR tuning of T cell subsets. Immunol Rev. 2018;283(1): 129-37.

15. Sakaguchi S, Wing K, Miyara M. Regulatory T cells_-a brief history and perspective. Eur J Immunol. 2007;37(Suppl 1):S116-23.

16. Harrington $L E$, et al. Interleukin 17-producing CD4+ effector T cells develop via a lineage distinct from the Thelper type 1 and 2 lineages. Nat Immunol. 2005;6(11):1123-32.

17. Dai J, et al. Metabolism-associated danger signal-induced immune response and reverse immune checkpoint-activated CD40(+) monocyte differentiation. J Hematol Oncol. 2017;10(1):141.

18. Hsieh CS, et al. Development of TH1 CD4+ T cells through IL-12 produced by Listeria-induced macrophages. Science. 1993;260(5107):547-9.

19. Schmitt $\mathrm{N}$, Ueno H. Regulation of human helper T cell subset differentiation by cytokines. Curr Opin Immunol. 2015;34:130-6.

20. Littman DR, Rudensky AY. Th17 and regulatory T cells in mediating and restraining inflammation. Cell. 2010;140(6):845-58.

21. Tran DQ, Ramsey H, Shevach EM. Induction of FOXP3 expression in naive human CD4+FOXP3 T cells by T-cell receptor stimulation is transforming growth factor-beta dependent but does not confer a regulatory phenotype. Blood. 2007;110(8):2983-90.

22. Cambier JC, et al. B-cell anergy: from transgenic models to naturally occurring anergic B cells? Nat Rev Immunol. 2007;7(8):633-43.

23. Jacobi AM, Diamond B. Balancing diversity and tolerance: lessons from patients with systemic lupus erythematosus. J Exp Med. 2005;202(3):341-4.

24. Galy A, et al. Human T, B, natural killer, and dendritic cells arise from a common bone marrow progenitor cell subset. Immunity. 1995;3(4):459-73.

25. Kondo M, Weissman IL, Akashi K. Identification of clonogenic common lymphoid progenitors in mouse bone marrow. Cell. 1997;91(5):661-72.

26. Gasteiger $\mathrm{G}$, Rudensky AY. Interactions between innate and adaptive Iymphocytes. Nat Rev Immunol. 2014;14(9):631-9.

27. Bostik P, et al. Innate immune natural killer cells and their role in HIV and SIV infection. HIV Ther. 2010;4(4):483-504.

28. Steinman RM, Cohn ZA. Identification of a novel cell type in peripheral lymphoid organs of mice. II. Functional properties in vitro. J Exp Med. 1974; 139(2):380-97.

29. Steinman RM, Cohn ZA. Identification of a novel cell type in peripheral lymphoid organs of mice. I. Morphology, quantitation, tissue distribution. J Exp Med. 1973;137(5):1142-62.

30. Shortman K, Heath WR. The CD8+ dendritic cell subset. Immunol Rev. 2010; 234(1):18-31.

31. Helft J, et al. Origin and functional heterogeneity of non-lymphoid tissue dendritic cells in mice. Immunol Rev. 2010;234(1):55-75.

32. Colonna M, Trinchieri G, Liu YJ. Plasmacytoid dendritic cells in immunity. Nat Immunol. 2004:5(12):1219-26.

33. Liu K, et al. In vivo analysis of dendritic cell development and homeostasis. Science. 2009:324(5925):392-7.

34. Murphy TL, et al. Transcriptional control of dendritic cell development. Annu Rev Immunol. 2016:34:93-119.

35. Cisse B, et al. Transcription factor E2-2 is an essential and specific regulator of plasmacytoid dendritic cell development. Cell. 2008;135(1): $37-48$. 
36. Bender A, et al. Improved methods for the generation of dendritic cells from nonproliferating progenitors in human blood. J Immunol Methods. 1996;196(2):121-35.

37. Appleby $L$, et al. Sources of heterogeneity in human monocyte subsets. Immunol Lett. 2013;152(1):32-41.

38. Yang J, et al. Monocyte and macrophage differentiation: circulation inflammatory monocyte as biomarker for inflammatory diseases. Biomark Res. 2014;2(1):1.

39. Yang J, et al. Chronic kidney disease induces inflammatory CD40+ monocyte differentiation via homocysteine elevation and DNA hypomethylation. Circ Res. 2016;119(11):1226-41.

40. Palframan RT, et al. Inflammatory chemokine transport and presentation in HEV: a remote control mechanism for monocyte recruitment to lymph nodes in inflamed tissues. J Exp Med. 2001;194(9):1361-73.

41. Leon B, et al. Dendritic cell differentiation potential of mouse monocytes: monocytes represent immediate precursors of CD8- and CD8+ splenic dendritic cells. Blood. 2004;103(7):2668-76.

42. Jung $\mathrm{S}$, et al. Analysis of fractalkine receptor CX(3)CR1 function by targeted deletion and green fluorescent protein reporter gene insertion. Mol Cell Biol. 2000;20(11):4106-14.

43. Fleming TJ, Fleming ML, Malek TR. Selective expression of Ly- $6 \mathrm{G}$ on myeloid lineage cells in mouse bone marrow. RB6-8C5 mAb to granulocytedifferentiation antigen (Gr-1) detects members of the Ly- 6 family. J Immunol. 1993;151(5):2399-408.

44. Nahrendorf $M$, et al. The healing myocardium sequentially mobilizes two monocyte subsets with divergent and complementary functions. J Exp Med. 2007;204(12):3037-47.

45. Van Furth R, Diesselhoff-den Dulk MC, Mattie H. Quantitative study on the production and kinetics of mononuclear phagocytes during an acute inflammatory reaction. J Exp Med. 1973;138(6):1314-30.

46. Nathan CF, et al. Identification of interferon-gamma as the lymphokine that activates human macrophage oxidative metabolism and antimicrobial activity. J Exp Med. 1983;158(3):670-89.

47. Ginhoux F, et al. Fate mapping analysis reveals that adult microglia derive from primitive macrophages. Science. 2010;330(6005):841-5.

48. Rosenfeld ME. Converting smooth muscle cells to macrophage-like cells with KLF4 in atherosclerotic plaques. Nat Med. 2015;21(6):549-51.

49. Hong CW. Current understanding in neutrophil differentiation and heterogeneity. Immune Netw. 2017;17(5):298-306.

50. Arock M. Mast cell differentiation: still open questions? Blood. 2016;127(4): 373-4.

51. Dahlin JS, et al. Lineage- CD34hi CD117int/hi FcepsilonRI+ cells in human blood constitute a rare population of mast cell progenitors. Blood. 2016; 127(4):383-91.

52. Shan $Y$, et al. Increased frequency of peripheral blood follicular helper $T$ cells and elevated serum IL21 levels in patients with knee osteoarthritis. Mol Med Rep. 2017:15(3):1095-102.

53. Morita R, et al. Human blood CXCR5(+)CD4(+) T cells are counterparts of $T$ follicular cells and contain specific subsets that differentially support antibody secretion. Immunity. 2011;34(1):108-21.

54. Victora GD, et al. Germinal center dynamics revealed by multiphoton microscopy with a photoactivatable fluorescent reporter. Cell. 2010;143(4): 592-605.

55. Duhen $\mathrm{T}$, et al. Production of interleukin 22 but not interleukin 17 by a subset of human skin-homing memory T cells. Nat Immunol. 2009;10(8): 857-63

56. Sallusto F, Zielinski CE, Lanzavecchia A. Human Th17 subsets. Eur J Immunol. 2012;42(9):2215-20.

57. Kuang DM, et al. B7-H1-expressing antigen-presenting cells mediate polarization of protumorigenic Th22 subsets. J Clin Invest. 2014;124(10): 4657-67.

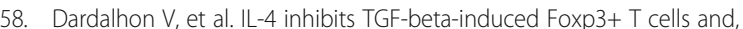
together with TGF-beta, generates IL-9+ IL-10+ Foxp3(-) effector T cells. Nat Immunol. 2008;9(12):1347-55.

59. Allman D, Pillai S. Peripheral B cell subsets. Curr Opin Immunol. 2008;20(2): 149-57.

60. Moller B, et al. Class-switched B cells display response to therapeutic B-cell depletion in rheumatoid arthritis. Arthritis Res Ther. 2009;11(3):R62.

61. Genestier $L$, et al. TLR agonists selectively promote terminal plasma cell differentiation of B cell subsets specialized in thymus-independent responses. J Immunol. 2007;178(12):7779-86.
62. Thiriot A, et al. The Bw cells, a novel B cell population conserved in the whole genus Mus. J Immunol. 2007:179(10):6568-78.

63. Haas KM, et al. B-1a and B-1b cells exhibit distinct developmental requirements and have unique functional roles in innate and adaptive immunity to S. pneumoniae. Immunity. 2005;23(1):7-18.

64. Nussenzweig MC, et al. Dendritic cells are accessory cells for the development of anti-trinitrophenyl cytotoxic T lymphocytes. J Exp Med. 1980;152(4):1070-84

65. Wakim LM, et al. Dendritic cell-induced memory T cell activation in nonlymphoid tissues. Science. 2008;319(5860):198-202.

66. Gardner A, Ruffell B. moDCs, less problems. Immunity. 2018;48(1):6-8.

67. Reizis $B$, et al. Plasmacytoid dendritic cells: recent progress and open questions. Annu Rev Immunol. 2011:29:163-83.

68. Macal, M., et al., Self-renewal and toll-like receptor signaling sustain exhausted plasmacytoid dendritic cells during chronic viral infection. Immunity, 2018. 48(4): p. 730-744 e5.

69. Bedoui $\mathrm{S}$, et al. Cross-presentation of viral and self antigens by skin-derived CD103+ dendritic cells. Nat Immunol. 2009;10(5):488-95.

70. Hildner K, et al. Batf3 deficiency reveals a critical role for CD8alpha+ dendritic cells in cytotoxic T cell immunity. Science. 2008;322(5904):1097100.

71. Merad $\mathrm{M}$, et al. The dendritic cell lineage: ontogeny and function of dendritic cells and their subsets in the steady state and the inflamed setting. Annu Rev Immunol. 2013;31:563-604.

72. Yona S, Jung S. Monocytes: subsets, origins, fates and functions. Curr Opin Hematol. 2010;17(1):53-9.

73. Cros J, et al. Human CD14dim monocytes patrol and sense nucleic acids and viruses via TLR7 and TLR8 receptors. Immunity. 2010;33(3):375-86.

74. Mukherjee $\mathrm{R}$, et al. Non-classical monocytes display inflammatory features: validation in sepsis and systemic lupus erythematous. Sci Rep. 2015:5:13886.

75. Boyette, L.B., et al., Phenotype, function, and differentiation potential of human monocyte subsets. PLoS One, 2017. 12(4): p. e0176460.

76. Robbins $\mathrm{SH}$, et al. Novel insights into the relationships between dendritic cell subsets in human and mouse revealed by genome-wide expression profiling. Genome Biol. 2008;9(1):R17.

77. Barbet, G., et al., Sensing microbial viability through bacterial RNA augments T follicular helper cell and antibody responses. Immunity, 2018. 48(3): p. 584-598 e5.

78. Murray PJ, Wynn TA. Protective and pathogenic functions of macrophage subsets. Nat Rev Immunol. 2011:11(11):723-37.

79. Yang L, Zhang Y. Tumor-associated macrophages: from basic research to clinical application. J Hematol Oncol. 2017;10(1):58.

80. Sutterwala FS, et al. Reversal of proinflammatory responses by ligating the macrophage Fcgamma receptor type I. J Exp Med. 1998;188(1):217-22.

81. Yang L, Zhang Y. Tumor-associated macrophages. potential targets for cancer treatment Biomark Res. 2017:5:25.

82. Edwards JP, et al. Biochemical and functional characterization of three activated macrophage populations. J Leukoc Biol. 2006;80(6):1298-307.

83. Anderson CF, Mosser DM. A novel phenotype for an activated macrophage: the type 2 activated macrophage. J Leukoc Biol. 2002;72(1):101-6.

84. Lu J, et al. Discrete functions of M2a and M2c macrophage subsets determine their relative efficacy in treating chronic kidney disease. Kidney Int. 2013:84(4):745-55.

85. Butcher MJ, Galkina EV. Phenotypic and functional heterogeneity of macrophages and dendritic cell subsets in the healthy and atherosclerosisprone aorta. Front Physiol. 2012;3:44.

86. Gleissner CA, et al. CXC chemokine ligand 4 induces a unique transcriptome in monocyte-derived macrophages. J Immunol. 2010;184(9):4810-8.

87. Kadl A, et al. Identification of a novel macrophage phenotype that develops in response to atherogenic phospholipids via Nrf2. Circ Res. 2010;107(6): 737-46.

88. Boyle JJ, et al. Coronary intraplaque hemorrhage evokes a novel atheroprotective macrophage phenotype. Am J Pathol. 2009;174(3):1097-108.

89. Pourcet B, Staels B. Alternative macrophages in atherosclerosis: not always protective! J Clin Invest. 2018;128(3):910-2

90. Li $\mathrm{X}$, et al. Mitochondrial reactive oxygen species mediate lysophosphatidylcholine-induced endothelial cell activation. Arterioscler Thromb Vasc Biol. 2016:36(6):1090-100.

91. Rombouts, M., et al., Linking CD11b (+) dendritic cells and natural killer T cells to plaque inflammation in atherosclerosis. Mediat Inflamm, 2016. 2016: p. 6467375 
92. Martinez-Rodriguez JE, et al. Expansion of the NKG2C+ natural killer-cell subset is associated with high-risk carotid atherosclerotic plaques in seropositive patients for human cytomegalovirus. Arterioscler Thromb Vasc Biol. 2013:33(11):2653-9.

93. Winchester $R$, et al. Association of elevations of specific $T$ cell and monocyte subpopulations in rheumatoid arthritis with subclinical coronary artery atherosclerosis. Arthritis Rheumatol. 2016;68(1):92-102.

94. Mrakovcic-Sutic l, et al. Cross-talk between NKT and regulatory T cells (Tregs) in modulation of immune response in patients with colorectal cancer following different pain management techniques. Coll Antropol. 2011;35(Suppl 2):57-60.

95. Dragu $\mathrm{R}$, et al. Predictive value of white blood cell subtypes for longterm outcome following myocardial infarction. Atherosclerosis. 2008; 196(1):405-12.

96. Li S, et al. Association of plasma PCSK9 levels with white blood cell count and its subsets in patients with stable coronary artery disease. Atherosclerosis. 2014:234(2):441-5.

97. Lievens $D$, et al. Abrogated transforming growth factor beta receptor II (TGFbetaRII) signalling in dendritic cells promotes immune reactivity of $T$ cells resulting in enhanced atherosclerosis. Eur Heart J. 2013;34(48):3717-27.

98. Caligiuri $\mathrm{G}$, et al. Protective immunity against atherosclerosis carried by $\mathrm{B}$ cells of hypercholesterolemic mice. J Clin Invest. 2002;109(6):745-53.

99. Liu X, et al. Is CD47 an innate immune checkpoint for tumor evasion? J Hematol Oncol. 2017;10(1):12.

100. Tapp LD, et al. TLR4 expression on monocyte subsets in myocardial infarction. J Intern Med. 2013;273(3):294-305.

101. Dworacka M, et al. Circulating CD3+56+ cell subset in pre-diabetes. Exp Clin Endocrinol Diabetes. 2014;122(2):65-70.

102. Cochain C, et al. CD8+ T cells regulate monopoiesis and circulating Ly6C-high monocyte levels in atherosclerosis in mice. Circ Res. 2015; 117(3):244-53.

103. Buono C, et al. T-bet deficiency reduces atherosclerosis and alters plaque antigen-specific immune responses. Proc Natl Acad Sci U S A. 2005;102(5): 1596-601.

104. Taleb S, Tedgui A, Mallat Z. IL-17 and Th17 cells in atherosclerosis: subtle and contextual roles. Arterioscler Thromb Vasc Biol. 2015;35(2):258-64.

105. Winer S, et al. Obesity predisposes to Th17 bias. Eur J Immunol. 2009;39(9): 2629-35.

106. Pastrana JL, et al. Regulatory $T$ cells and atherosclerosis. J Clin Exp Cardiolog. 2012;2012(Suppl 12):2

107. Satoh $\mathrm{S}$, et al. Relationships between inflammatory mediators and coronary plaque composition in patients with stable angina investigated by ultrasound radiofrequency data analysis. Cardiovasc Interv Ther. 2011;26(3): 193-201.

108. Rosenfeld SM, et al. B-1b cells secrete atheroprotective IgM and attenuate atherosclerosis. Circ Res. 2015;117(3):e28-39.

109. Mohanta SK, et al. Artery tertiary lymphoid organs contribute to innate and adaptive immune responses in advanced mouse atherosclerosis. Circ Res. 2014;114(11):1772-87.

110. Jonasson L, Backteman K, Ernerudh J. Loss of natural killer cell activity in patients with coronary artery disease. Atherosclerosis. 2005;183(2):316-21.

111. Busch $M$, et al. Dendritic cell subset distributions in the aorta in healthy and atherosclerotic mice. PLoS One. 2014;9(2):e88452.

112. Jaipersad AS, et al. Expression of monocyte subsets and angiogenic markers in relation to carotid plaque neovascularization in patients with pre-existing coronary artery disease and carotid stenosis. Ann Med. 2014;46(7):530-8.

113. Czepluch FS, et al. Increased proatherogenic monocyte-platelet cross-talk in monocyte subpopulations of patients with stable coronary artery disease. J Intern Med. 2014;275(2):144-54

114. Poitou C, et al. CD14dimCD16+ and CD14+CD16+ monocytes in obesity and during weight loss: relationships with fat mass and subclinical atherosclerosis. Arterioscler Thromb Vasc Biol. 2011;31(10):2322-30.

115. Imanishi T, et al. Association of monocyte subset counts with coronary fibrous cap thickness in patients with unstable angina pectoris. Atherosclerosis. 2010;212(2):628-35.

116. Lee JW, et al. Proinflammatory CD14(+)CD16(+) monocytes are associated with vascular stiffness in predialysis patients with chronic kidney disease. Kidney Res Clin Pract. 2013;32(4):147-52.

117. Rothe $\mathrm{G}$, et al. A more mature phenotype of blood mononuclear phagocytes is induced by fluvastatin treatment in hypercholesterolemic patients with coronary heart disease. Atherosclerosis. 1999;144(1):251-61.
118. Li, T., et al., Huanglian jiedu decoction regulated and controlled differentiation of monocytes, macrophages, and foam cells: an experimental study. Zhongguo Zhong Xi Yi Jie He Za Zhi, 2014. 34(9): p. 1096-1102.

119. Medina I, et al. Hck/Fgr kinase deficiency reduces plaque growth and stability by blunting monocyte recruitment and intraplaque motility. Circulation. 2015;132(6):490-501.

120. Zhang, D., et al., Severe hyperhomocysteinemia promotes bone marrowderived and resident inflammatory monocyte differentiation and atherosclerosis in LDLr/CBS-deficient mice. Circ Res, 2012. 111(1): p. 37-49.

121. Donners MM, et al. Hematopoietic miR155 deficiency enhances atherosclerosis and decreases plaque stability in hyperlipidemic mice. PLoS One. 2012;7(4):e35877.

122. Fang $P$, et al. Hyperhomocysteinemia potentiates hyperglycemia-induced inflammatory monocyte differentiation and atherosclerosis. Diabetes. 2014; 63(12):4275-90.

123. Stoger $J$, et al. Distribution of macrophage polarization markers in human atherosclerosis. Atherosclerosis. 2012;225(2):461-8.

124. Hu Y, et al. Class A scavenger receptor attenuates myocardial infarctioninduced cardiomyocyte necrosis through suppressing M1 macrophage subset polarization. Basic Res Cardiol. 2011;106(6):1311-28.

125. Alipour A, et al. Leukocyte activation by triglyceride-rich lipoproteins. Arterioscler Thromb Vasc Biol. 2008;28(4):792-7.

126. Soehnlein O, Lindbom L, Weber C. Mechanisms underlying neutrophilmediated monocyte recruitment. Blood. 2009;114(21):4613-23.

127. Gombart AF, et al. Aberrant expression of neutrophil and macrophagerelated genes in a murine model for human neutrophil-specific granule deficiency. J Leukoc Biol. 2005;78(5):1153-65.

128. Ionita MG, et al. High neutrophil numbers in human carotid atherosclerotic plaques are associated with characteristics of rupture-prone lesions. Arterioscler Thromb Vasc Biol. 2010;30(9):1842-8.

129. Tanaka M, et al. Eosinophil count is positively correlated with coronary artery calcification. Hypertens Res. 2012;35(3):325-8.

130. Serhan CN, Savill J. Resolution of inflammation: the beginning programs the end. Nat Immunol. 2005;6(12):1191-7.

131. Soylu K, et al. The effect of blood cell count on coronary flow in patients with coronary slow flow phenomenon. Pak J Med Sci. 2014;30(5):936-41.

132. Bot I, Shi GP, Kovanen PT. Mast cells as effectors in atherosclerosis. Arterioscler Thromb Vasc Biol. 2015;35(2):265-71.

133. Wu, C., et al., Characterization of IL-12 receptor beta1 chain (IL-12Rbeta1)deficient mice: IL-12Rbeta1 is an essential component of the functional mouse IL-12 receptor. J Immunol, 1997. 159(4): p. 1658-65.

134. Letimier FA, et al. Chromatin remodeling by the SWI/SNF-like BAF complex and STAT4 activation synergistically induce IL-12Rbeta2 expression during human Th1 cell differentiation. EMBO J. 2007;26(5):1292-302.

135. Afkarian $M$, et al. T-bet is a STAT1-induced regulator of $I L-12 R$ expression in naive CD4+ T cells. Nat Immunol. 2002;3(6):549-57.

136. Athie-Morales $V$, et al. Sustained IL-12 signaling is required for Th1 development. J Immunol. 2004;172(1):61-9.

137. Wurster AL, Tanaka T, Grusby MJ. The biology of Stat4 and Stat6. Oncogene. 2000;19(21):2577-84.

138. Kelly-Welch $A E$, et al. Interleukin-4 and interleukin-13 signaling connections maps. Science. 2003;300(5625):1527-8.

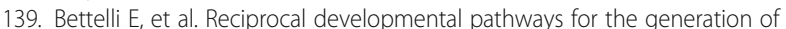
pathogenic effector TH17 and regulatory T cells. Nature. 2006;441(7090): 235-8.

140. O'Shea JJ, et al. Signal transduction and Th17 cell differentiation. Microbes Infect. 2009;11(5):599-611.

141. Ichiyama K, et al. Foxp3 inhibits RORgammat-mediated IL-17A mRNA transcription through direct interaction with RORgammat. J Biol Chem. 2008;283(25):17003-8

142. Li MO, Rudensky AY. T cell receptor signalling in the control of regulatory $T$ cell differentiation and function. Nat Rev Immunol. 2016;16(4):220-33.

143. Tone $Y$, et al. Smad3 and NFAT cooperate to induce Foxp3 expression through its enhancer. Nat Immunol. 2008;9(2):194-202.

144. Webster KE, et al. In vivo expansion of T reg cells with IL-2-mAb complexes: induction of resistance to EAE and long-term acceptance of islet allografts without immunosuppression. J Exp Med. 2009;206(4):751-60.

145. Niiro H, Clark EA. Regulation of B-cell fate by antigen-receptor signals. Nat Rev Immunol. 2002;2(12):945-56.

146. Kurosaki T. Genetic analysis of B cell antigen receptor signaling. Annu Rev Immunol. 1999;17:555-92. 
147. Garraud O, et al. Revisiting the B-cell compartment in mouse and humans: more than one B-cell subset exists in the marginal zone and beyond. BMC Immunol. 2012;13:63.

148. Cariappa A, et al. The follicular versus marginal zone B lymphocyte cell fate decision is regulated by Aiolos, Btk, and CD21. Immunity. 2001; 14(5):603-15

149. Croker BA, et al. The Rac2 guanosine triphosphatase regulates B lymphocyte antigen receptor responses and chemotaxis and is required for establishment of B-1a and marginal zone B lymphocytes. J Immunol. 2002; 168(7):3376-86.

150. Thome M. CARMA1, BCL-10 and MALT1 in lymphocyte development and activation. Nat Rev Immunol. 2004;4(5):348-59.

151. Rickert RC, Jellusova J, Miletic AV. Signaling by the tumor necrosis factor receptor superfamily in B-cell biology and disease. Immunol Rev. 2011; 244(1):115-33.

152. Mildner A, Jung S. Development and function of dendritic cell subsets. Immunity. 2014:40(5):642-56.

153. Murphy KM. Transcriptional control of dendritic cell development. Adv Immunol. 2013:120:239-67.

154. Ginhoux F, et al. The origin and development of nonlymphoid tissue CD103 + DCs. J Exp Med. 2009;206(13):3115-30.

155. Hacker $C$, et al. Transcriptional profiling identifies ld 2 function in dendritic cell development. Nat Immunol. 2003;4(4):380-6.

156. Tamura $T$, et al. IFN regulatory factor -4 and -8 govern dendritic cell subset development and their functional diversity. J Immunol. 2005;174(5):2573-81.

157. Becker AM, et al. IRF-8 extinguishes neutrophil production and promotes dendritic cell lineage commitment in both myeloid and lymphoid mouse progenitors. Blood. 2012;119(9):2003-12.

158. Spranger S, Bao R, Gajewski TF. Melanoma-intrinsic beta-catenin signalling prevents anti-tumour immunity. Nature. 2015;523(7559):231-5.

159. Spranger, S., et al., Tumor-residing Batf3 dendritic cells are required for effector T cell trafficking and adoptive T cell therapy. Cancer Cell, 2017. 31(5): p. 711-723 e4

160. Wu $\mathrm{L}$, et al. RelB is essential for the development of myeloid-related CD8alpha- dendritic cells but not of lymphoid-related CD8alpha+ dendritic cells. Immunity. 1998:9(6):839-47.

161. Lewis $\mathrm{KL}$, et al. Notch2 receptor signaling controls functional differentiation of dendritic cells in the spleen and intestine. Immunity. 2011;35(5):780-91.

162. Caton ML, Smith-Raska MR, Reizis B. Notch-RBP-J signaling controls the homeostasis of CD8- dendritic cells in the spleen. J Exp Med. 2007;204(7): 1653-64.

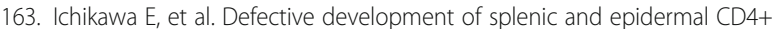
dendritic cells in mice deficient for IFN regulatory factor-2. Proc Natl Acad Sci U S A. 2004;101(11):3909-14.

164. Suzuki, S., et al., Critical roles of interferon regulatory factor 4 in CD11bhighCD8alpha- dendritic cell development. Proc Natl Acad Sci U S A, 2004. 101(24): p. 8981-6.

165. Vander Lugt B, et al. Transcriptional programming of dendritic cells for enhanced MHC class II antigen presentation. Nat Immunol. 2014;15(2):161-7.

166. Bajana S, et al. IRF4 promotes cutaneous dendritic cell migration to lymph nodes during homeostasis and inflammation. J Immunol. 2012; 189(7):3368-77.

167. Naik SH, et al. Cutting edge: generation of splenic CD8+ and CD8- dendritic cell equivalents in Fms-like tyrosine kinase 3 ligand bone marrow cultures. J Immunol. 2005:174(11):6592-7.

168. Laouar $Y$, et al. STAT3 is required for Flt3L-dependent dendritic cell differentiation. Immunity. 2003;19(6):903-12.

169. Ghosh HS, et al. Continuous expression of the transcription factor e2-2 maintains the cell fate of mature plasmacytoid dendritic cells. Immunity. 2010;33(6):905-16

170. Serbina NV, et al. Sequential MyD88-independent and -dependent activation of innate immune responses to intracellular bacterial infection. Immunity. 2003;19(6):891-901.

171. De Trez C, et al. iNOS-producing inflammatory dendritic cells constitute the major infected cell type during the chronic Leishmania major infection phase of C57BL/6 resistant mice. PLoS Pathog. 2009;5(6):e1000494.

172. Seo SU, et al. Type I interferon signaling regulates Ly6C(hi) monocytes and neutrophils during acute viral pneumonia in mice. PLoS Pathog. 2011;7(2): e1001304.

173. Iwasaki H, Akashi K. Myeloid lineage commitment from the hematopoietic stem cell. Immunity. 2007;26(6):726-40.
174. Zhu YP, Thomas GD, Hedrick CC. 2014 Jeffrey M. Hoeg award lecture: transcriptional control of monocyte development. Arterioscler Thromb Vasc Biol. 2016;36(9):1722-33.

175. Alder JK, et al. Kruppel-like factor 4 is essential for inflammatory monocyte differentiation in vivo. J Immunol. 2008;180(8):5645-52.

176. Kurotaki D, et al. Essential role of the IRF8-KLF4 transcription factor cascade in murine monocyte differentiation. Blood. 2013;121(10):1839-49.

177. Carlin LM, et al. Nr4a1-dependent Ly6C(low) monocytes monitor endothelial cells and orchestrate their disposal. Cell. 2013;153(2):362-75.

178. Hanna RN, et al. The transcription factor NR4A1 (Nur77) controls bone marrow differentiation and the survival of Ly6C- monocytes. Nat Immunol. 2011;12(8):778-85

179. Qin $\mathrm{H}$, et al. LPS induces CD40 gene expression through the activation of NF-kappaB and STAT-1alpha in macrophages and microglia. Blood. 2005; 106(9):3114-22.

180. Wang N, Liang $H$, Zen K. Molecular mechanisms that influence the macrophage m1-m2 polarization balance. Front Immunol. 2014:5:614

181. Krausgruber $\mathrm{T}$, et al. IRF5 promotes inflammatory macrophage polarization and TH1-TH17 responses. Nat Immunol. 2011;12(3):231-8.

182. Donlin LT, et al. Modulation of TNF-induced macrophage polarization by synovial fibroblasts. J Immunol. 2014;193(5):2373-83.

183. Tschopp J, Martinon F, Burns K. NALPs: a novel protein family involved in inflammation. Nat Rev Mol Cell Biol. 2003;4(2):95-104.

184. Imtiyaz HZ, Simon MC. Hypoxia-inducible factors as essential regulators of inflammation. Curr Top Microbiol Immunol. 2010;345:105-20.

185. Cramer T, et al. HIF-1alpha is essential for myeloid cell-mediated inflammation. Cell. 2003;112(5):645-57.

186. Rius J, et al. NF-kappaB links innate immunity to the hypoxic response through transcriptional regulation of HIF-1alpha. Nature. 2008;453(7196):807-11.

187. Nizet $\mathrm{V}$, Johnson RS. Interdependence of hypoxic and innate immune responses. Nat Rev Immunol. 2009;9(9):609-17.

188. O'Farrell AM, et al. IL-10 inhibits macrophage activation and proliferation by distinct signaling mechanisms: evidence for Stat3-dependent and -independent pathways. EMBO J. 1998;17(4):1006-18.

189. Bouhlel MA, et al. PPARgamma activation primes human monocytes into alternative M2 macrophages with anti-inflammatory properties. Cell Metab. 2007;6(2):137-43.

190. Liao X, et al. Kruppel-like factor 4 regulates macrophage polarization. J Clin Invest. 2011;121(7):2736-49.

191. Sharma N, et al. Myeloid Kruppel-like factor 4 deficiency augments atherogenesis in ApoE-/- mice-brief report. Arterioscler Thromb Vasc Biol. 2012;32(12):2836-8.

192. Babaev VR, et al. Conditional knockout of macrophage PPARgamma increases atherosclerosis in C57BL/6 and low-density lipoprotein receptordeficient mice. Arterioscler Thromb Vasc Biol. 2005:25(8):1647-53.

193. Van Ginderachter JA, et al. Macrophages, PPARs, and cancer. PPAR Res. 2008:2008:169414

194. Zhang W, Xu W, Xiong S. Macrophage differentiation and polarization via phosphatidylinositol 3-kinase/Akt-ERK signaling pathway conferred by serum amyloid P component. J Immunol. 2011;187(4):1764-77.

195. Zhang W, Xu W, Xiong S. Blockade of Notch1 signaling alleviates murine lupus via blunting macrophage activation and M2b polarization. J Immunol. 2010:184(11):6465-78.

196. Sica A, Mantovani A. Macrophage plasticity and polarization: in vivo veritas. J Clin Invest. 2012:122(3):787-95.

197. Moore KW, et al. Interleukin-10 and the interleukin-10 receptor. Annu Rev Immunol. 2001;19:683-765.

198. Murray PJ. Understanding and exploiting the endogenous interleukin-10/ STAT3-mediated anti-inflammatory response. Curr Opin Pharmacol. 2006: 6(4):379-86

199. Boyle JJ, et al. Activating transcription factor 1 directs Mhem atheroprotective macrophages through coordinated iron handling and foam cell protection. Circ Res. 2012;110(1):20-33.

200. Hayashi $C$, et al. Protective role for TLR4 signaling in atherosclerosis progression as revealed by infection with a common oral pathogen. $J$ Immunol. 2012;189(7):3681-8.

201. Clement $M$, et al. Control of the T follicular helper-germinal center Bcell axis by CD8(+) regulatory $T$ cells limits atherosclerosis and tertiary lymphoid organ development. Circulation. 2015;131(6):560-70.

202. Choi P, Reiser H. IL-4: role in disease and regulation of production. Clin Exp Immunol. 1998;113(3):317-9. 
203. Oriss, T.B., et al., Crossregulation between Thelper cell (Th)1 and Th2: inhibition of Th2 proliferation by IFN-gamma involves interference with IL-1. J Immunol, 1997. 158(8): p. 3666-72.

204. Laurence, A., et al., Interleukin-2 signaling via STAT5 constrains T helper 17 cell generation. Immunity, 2007. 26(3): p. 371-81.

205. Kimura A, Kishimoto T. IL-6: regulator of Treg/Th17 balance. Eur J Immunol. 2010;40(7):1830-5.

206. Chang JH, Chung Y. Regulatory T cells in B cell follicles. Immune Netw. 2014;14(5):227-36.

207. Wilson GL, et al. cDNA cloning of the B cell membrane protein CD22: a mediator of B-B cell interactions. J Exp Med. 1991;173(1):137-46.

208. Pao LI, et al. B cell-specific deletion of protein-tyrosine phosphatase Shp1 promotes B-1a cell development and causes systemic autoimmunity. Immunity. 2007;27(1):35-48.

209. Nguyen KD, et al. Circadian gene Bmal1 regulates diurnal oscillations of Ly6C(hi) inflammatory monocytes. Science. 2013;341(6153):1483-8.

210. Davison AM, King NJ. Accelerated dendritic cell differentiation from migrating Ly6C(lo) bone marrow monocytes in early dermal West Nile virus infection. J Immunol. 2011;186(4):2382-96.

211. Rackov, G., et al., p21 mediates macrophage reprogramming through regulation of p50-p50 NF-kappaB and IFN-beta. J Clin Invest, 2016. 126(8): p. 3089-3103.

212. Myers MP, et al. TYK2 and JAK2 are substrates of protein-tyrosine phosphatase 1B. J Biol Chem. 2001;276(51):47771-4.

213. Dickensheets $H$, et al. Suppressor of cytokine signaling-1 is an IL-4-inducible gene in macrophages and feedback inhibits IL-4 signaling. Genes Immun. 2007;8(1):21-7.

214. Liu G, Abraham E. MicroRNAs in immune response and macrophage polarization. Arterioscler Thromb Vasc Biol. 2013;33(2):170-7.

215. Menezes S, et al. The heterogeneity of Ly6C(hi) monocytes controls their differentiation into iNOS(+) macrophages or monocyte-derived dendritic cells. Immunity. 2016;45(6):1205-18.

216. Granot Z, et al. Tumor entrained neutrophils inhibit seeding in the premetastatic lung. Cancer Cell. 2011;20(3):300-14.

217. Yoshida GJ. The heterogeneity of cancer stem-like cells at the invasive front. Cancer Cell Int. 2017;17:23.

218. Ok CY, Young KH. Checkpoint inhibitors in hematological malignancies. J Hematol Oncol. 2017;10(1):103.

219. Jenkins RW, Barbie DA, Flaherty KT. Mechanisms of resistance to immune checkpoint inhibitors. Br J Cancer. 2018;118(1):9-16.

220. Kumar $\mathrm{V}$, et al. The nature of myeloid-derived suppressor cells in the tumor microenvironment. Trends Immunol. 2016;37(3):208-20.

221. Foks AC, et al. CD11b+Gr-1+ myeloid-derived suppressor cells reduce atherosclerotic lesion development in LDLr deficient mice. Cardiovasc Res. 2016;111(3):252-61.

222. Ostrand-Rosenberg S. Myeloid derived-suppressor cells: their role in cancer and obesity. Curr Opin Immunol. 2018;51:68-75.

223. Bronte $\mathrm{V}$, et al. Recommendations for myeloid-derived suppressor cell nomenclature and characterization standards. Nat Commun. 2016;7:12150.

224. Srivastava MK, et al. Myeloid suppressor cell depletion augments antitumor activity in lung cancer. PLoS One. 2012;7(7):e40677.

225. Stromnes IM, et al. Targeted depletion of an MDSC subset unmasks pancreatic ductal adenocarcinoma to adaptive immunity. Gut. 2014;63(11): 1769-81.

226. Trikha M, et al. Targeted anti-interleukin-6 monoclonal antibody therapy for cancer: a review of the rationale and clinical evidence. Clin Cancer Res. 2003;9(13):4653-65.

227. Guo Y, et al. Interleukin-6 signaling pathway in targeted therapy for cancer. Cancer Treat Rev. 2012:38(7):904-10.

228. Rossi JF, et al. Interleukin-6 as a therapeutic target. Clin Cancer Res. 2015; 21(6):1248-57.

Ready to submit your research? Choose BMC and benefit from:

- fast, convenient online submission

- thorough peer review by experienced researchers in your field

- rapid publication on acceptance

- support for research data, including large and complex data types

- gold Open Access which fosters wider collaboration and increased citations

- maximum visibility for your research: over $100 \mathrm{M}$ website views per year

At BMC, research is always in progress.

Learn more biomedcentral.com/submissions 